\title{
Using Pharmacology to Squeeze the Life Out of Childhood Leukemia, and Potential Strategies to Achieve Breakthroughs in Medulloblastoma Treatment
}

\author{
Juwina Wijaya, Tomoka Gose, and John D. Schuetz \\ Department of Pharmaceutical Sciences, St. Jude Children's Research Hospital, Memphis, Tennessee
}

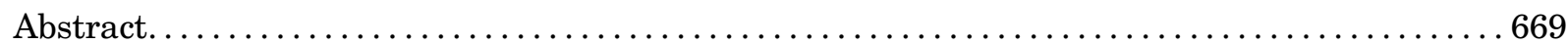

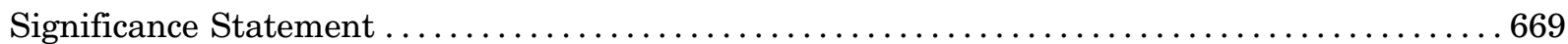

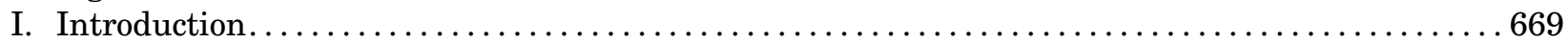

II. ALL: Development and Evolution of Pharmacotherapy to Cure Childhood Leukemias ........670

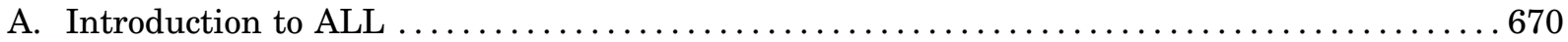

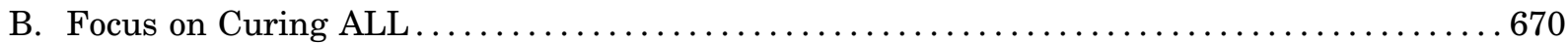

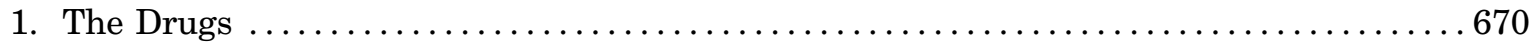

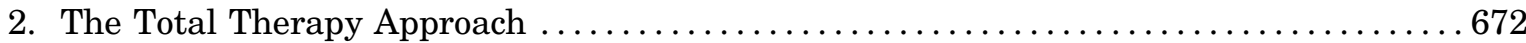

a. Era 1 (1962-1967) Total I-IV: increasing survival by reducing myelosuppression ...6672

b. Eras 2 and 3 (1967-1983) Total V-X: complete remission prolonged by intensive

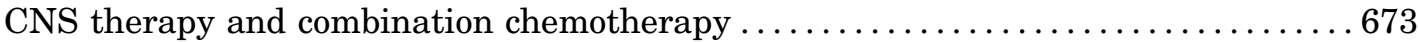

c. Era 4 (1984-1991) Total XI-XII: dose intensification and individualized pharmacokinetic analysis to improve outcome ......................... 674

d. Eras 5 and 6 (1991-2007) Total XIII-XV: reducing CNS relapse and individualizing treatment with pharmacogenomic analysis . . . . . . . . . . . . 675

3. Improving Therapy by Understanding the Underlying ALL Biology. . . . . . . . . 677

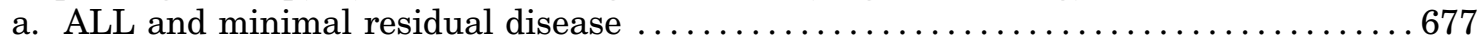

b. Genetic alterations influence ALL outcome .............................. 677

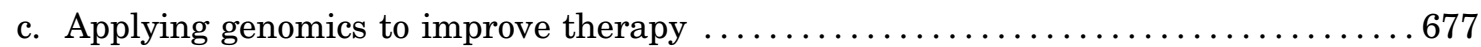

d. Immunotherapy, an emerging treatment modality $\ldots \ldots \ldots \ldots \ldots \ldots \ldots \ldots \ldots 678$

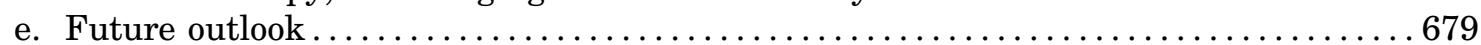

III. Medulloblastoma ................................................................. 680

A. Introduction to Medulloblastoma ......................................... 680

B. MB Classification to Understand Disease and Improve Therapy $\ldots \ldots \ldots \ldots \ldots \ldots \ldots \ldots 680$

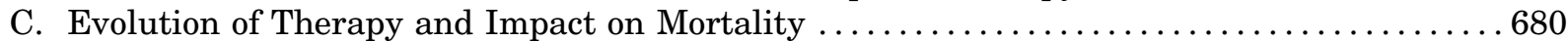

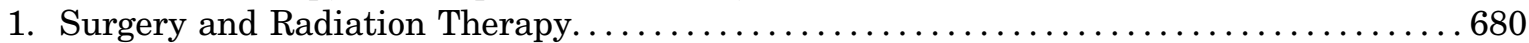

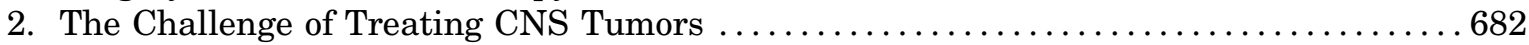

3. Using Molecular Subgrouping and Omics Studies to Improve Therapy ............ 683

D. Development of Models to Better Understand MB Biology and Develop New Therapies ...684

1. Immortalized Cell Lines and Those Derived from GEMMs.................... 684

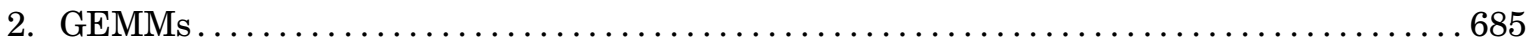

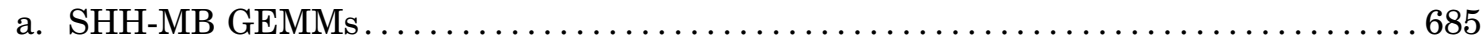

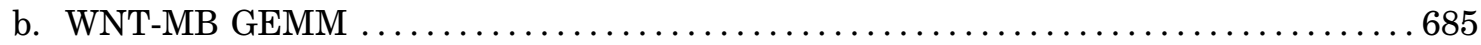

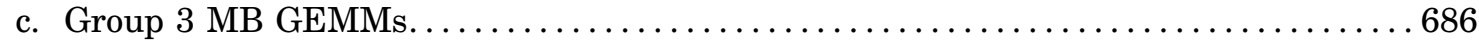

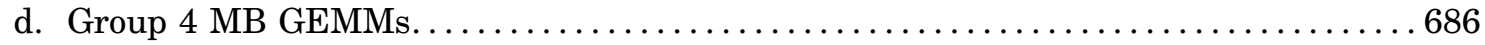

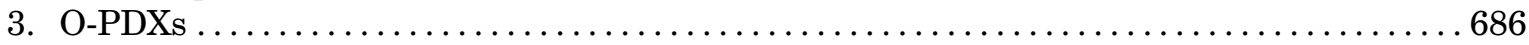

Address correspondence to: John D. Schuetz, Department of Pharmaceutical Sciences, MS 313, St. Jude Children's Research Hospital, 262 Danny Thomas Place, Memphis, TN 38105. E-mail: John.schuetz@stjude.org

This work was supported by NIH National Cancer Institute Grants R01 CA194057, CA194206 (J.D.S.), P30 CA21745, CA21865, and CA96832 and by American Lebanese Syrian Associated Charities (ALSAC).

J.W. and T.G. contributed equally to this work.

https://doi.org/10.1124/pr.118.016824. 
4. Three-Dimensional Organoids and Other Recent Advances ....................6 687

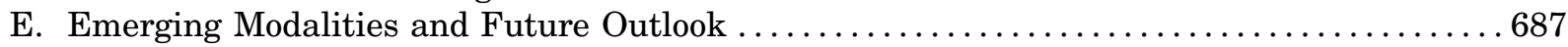

Acknowledgments ................................................... 688

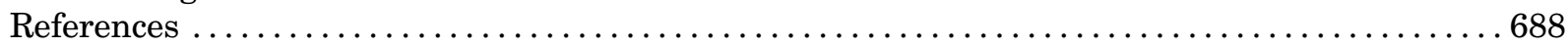

Abstract_-Eliminating cancer was once thought of as a war. This analogy is still apt today; however, we now realize that cancer is a much more formidable enemy than scientists originally perceived, and in some cases, it harbors a profound ability to thwart our best efforts to defeat it. However, before we were aware of the complexity of cancer, chemotherapy against childhood acute lymphoblastic leukemia (ALL) was successful because it applied the principles of pharmacology. Herein, we provide a historic perspective of the experience at St. Jude Children's Research Hospital. In 1962, when the hospital opened, fewer than $3 \%$ of patients experienced durable cure. Through judicious application of pharmacologic principles (e.g., combination therapy with agents using different mechanisms of action) plus appropriate drug scheduling, dosing, and pharmacodynamics, the survival of patients with ALL now exceeds $90 \%$. We contrast this approach to treating ALL with the contemporary approach to treating medulloblastoma, in which genetics and molecular signatures are being used to guide the development of more-efficacious treatment strategies with minimal toxicity. Finally, we highlight the emerging technologies that can sustain and propel the collaborative efforts to squeeze the life out of these cancers.

Significance Statement-Up until the early 1960 s, chemotherapy for childhood acute lymphoblastic leukemia was mostly ineffective. This changed with the knowledge and implementation of rational approaches to combination therapy. Although the therapeutics of brain cancers such as medulloblastoma are not as refined (in part because of the blood-brain barrier obstacle), recent extraordinary advances in knowledge of medulloblastoma pathobiology has led to innovations in disease classification accompanied with strategies to improve therapeutic outcomes. Undoubtedly, additional novel approaches, such as immunological therapeutics, will open new avenues to further the goal of taming cancer.

\section{Introduction}

A century ago, the idea that cancer could be cured was considered a pipe dream. Even with the development of powerful chemotherapeutic drugs, there was little initial success. Nonetheless, with purpose, perseverance, and focus, remarkable success has been achieved in treating some cancers, such as childhood acute lymphoblastic leukemia (ALL). For others, like the central nervous system (CNS) tumor medulloblastoma (MB), improving therapy has been more challenging.

After the National Aeronautics and Space Administration fulfilled President Kennedy's dream of landing a man on the moon in July 1969, many realized what could be achieved when federal funding was appropriated for a focused scientific endeavor. The public called for a "moonshot for cancer." On December 9, 1969, the
Citizens' Committee for the Conquest of Cancer, led by the well connected socialite and publicist Mary Lasker, published full-page advertisements in The Washington Post and The New York Times entitled "Mr. Nixon: you can cure cancer." Such grassroots efforts were supported by the the "father of modern chemotherapy," Dr. Sidney Farber, a pediatric pathologist working at Dana-Farber Cancer Institute (Boston, MA).

Two years later, President Nixon signed the National Cancer Act on December 23, 1971, in part, to bolster his sinking popularity due to the Vietnam war. He called the legislation a "national commitment for the conquest of cancer." Although Nixon did not explicitly refer to the conquest of cancer as a war, the metaphor was popular, and the act became widely known as the "war on cancer." The act expanded federal funding for cancer

ABBREVIATIONS: ABC, ATP-binding cassette transporter; ABL, Abelson; ACTH, adrenocorticotropic hormone; ALL, acute lymphoblastic leukemia; Ara-C, cytarabine; ASNase, asparaginase; BBB, blood-brain barrier; BCR, breakpoint cluster region; BiTE, bispecific T-cell engager; CAR, chimeric antigen receptor; CDK, cyclin-dependent kinase; CEP72, centrosomal protein 72; CNS, central nervous system; CRISPR, clustered regularly interspaced short palindromic repeats; CRLF2, cytokine receptor-like factor 2; CSF, cerebral spinal fluid; CSI, craniospinal irradiation; CYCLO, cyclophosphamide; Dex, dexamethasone; DHFR, dihydrofolate reductase; DNR, daunorubicin; DOX, doxorubicin; EP, etoposide; ERG, ETS transcription factor ERG; ETP, early T-cell precursor; ETV6, ETS variant transcription factor 6; FPGS, folylpolyglutamate synthetase; GEMM, genetically engineered mouse model; HDMTX, high-dose methotrexate; HGPRT, hypoxanthineguanine phosphoribosyl transferase; Hyd, hydrocortisone; iAMP21, intrachromosomal amplification of chromosome 21; InO, inotuzumab ozogamicin; JAK, Janus kinase; LYL1, lymphoblastic leukemia derived sequence 1; MB, medulloblastoma; MLL, mixed lineage leukemia; 6-MP, 6-mercaptopurine; MRD, minimal residual disease; MTHFR, methylenetetrahydrofolate reductase; MTX, methotrexate; MTX-PG, methotrexate polyglutamate; MYC, MYC proto-oncogene, bHLH transcription factor; O-PDX, orthotopic patient-derived xenograft; PBX1, pre-B-cell leukemia transcription factor 1; Ph, Philadelphia; PI3K, phoshatidylinostiol-3-kinase; Pred, prednisone or prednisolone; Ptc/Ptch, patched; RUNX1, runt-related transcription factor 1; scRNA-seq, single-cell RNA sequencing; SHH, sonic hedgehog; SMO, smoothened; SRC, SRC proto-oncogene; STAT, signal transducers and activators of transcription; TAL1, T-cell acute lymphocytic leukemia protein 1; TCF3, transcription factor 3; TEN, teniposide; TKI, tyrosine kinase inhibitor; TLX1, T cell leukemia homeobox 1; TLX3, T cell leukemia homeobox 3; TP53/Trp53, tumor protein 53; TPMT, thiopurine methyltransferase; TT, homozygous; VCR, vincristine; WNT, wingless. 
research and created the National Cancer Institute in Frederick, Maryland. Nixon hedged his bets: the initial funding for cancer research was substantial $(\$ 1.5$ billion), but it was available for only 3 years, and scientific understanding of the disease was still nascent.

Because our knowledge of cancer was so elementary at the time, there was substantial resistance in the scientific community; people considered the investment and promise of a cure to be premature. One vocal critic was Professor Sol Spiegelman, the director of the Institute of Cancer Research at Columbia College of Physicians and Surgeons (Manhattan, NY), who pointedly mocked the campaign by saying, "an all-out effort at this time [to find a cure for cancer] would be like trying to land a man on the moon without knowing Newton's laws of gravity." For certain cancers, such as $\mathrm{MB}$, this simile remains apt today. However, for childhood leukemia, cure rates that were in the single digits in 1969 are exceeding 90\% for some ALL subtypes today. This achievement was only possible through the concerted and cooperative efforts of many researchers.

This review profiles the advances in therapy, highlighting how key principles of pharmacology were used for more than 55 years, by researchers at St. Jude Children's Research Hospital (St. Jude), to develop ALL protocols that have proven to be beneficial to many children. The second part of the review highlights the continuing challenges of improving outcomes for MB, the most frequent CNS tumor in children. We selected MB to not only underscore the problems of treating a cancer that arises behind the blood-brain barrier (BBB) but also illustrate how advances in MB treatment can coevolve with advances in our understanding of the pathogenesis of the disease. Contemporary omics studies of MB have propelled the field and led to a rapid expansion in knowledge of MB subgroups, understanding of their oncogenic drivers, and engineering of model systems to aid in the development of new, more effective therapies.

\section{ALL: Development and Evolution of Pharmacotherapy to Cure Childhood Leukemias}

\section{A. Introduction to $A L L$}

ALL is the most common childhood cancer, accounting for 25\% of all cases (Pui, 1995). Despite cure rates exceeding $90 \%$ in children, ALL remains a leading cause of morbidity and mortality among them (Pui and Evans, 2013). Patients with ALL typically present with symptoms related to anemia, thrombocytopenia, and neutropenia as the tumor replaces the bone marrow. The malignancy also causes uncontrolled proliferation of abnormal, immature lymphocytes and their progenitors in either the B- or T-cell lineage (Terwilliger and AbdulHay, 2017). Symptoms can include frequent infections, fever, easy bruising, bleeding that is hard to stop, and flat, dark-red spots (petechiae) caused by bleeding under the skin. Involvement of the CNS remains a major challenge in clinical management of ALL. The molecular mechanisms and pathways mediating leukemic cell entry into the CNS have not been completely elucidated.

Here, we provide a historic perspective and evolving conceptual basis for curative chemotherapy for ALL, as an example of a potential pharmacologic paradigm: successive improvements in survival, driven mostly by pharmacologic modifications, and tested in randomized clinical trials.

\section{B. Focus on Curing $A L L$}

1. The Drugs. Prior to the use of chemotherapy, blood transfusion (used until the mid-1940s) was the only therapy for ALL, and all it achieved was to delay the inevitable-death caused by hemorrhage and infection. The first blood transfusion administered to a patient with leukemia was performed by George Callender at St. Bartholomew's Hospital in London in 1873; it was understood that leukemia was a disease of the blood (Piller, 2001). The transfusion provided about 6 weeks of relief for the patient. Blood transfusion as a treatment of acute leukemia was first attempted in the mid-19th century, and the first complete blood transfusion to treat leukemia was given by Bessis and Bernard (1947). The result was a temporary remission that lasted a few months (remission of acute leukemia was almost unheard of at that time). However, ALL was uniformly fatal; most children survived only 2 to 3 months after diagnosis.

Insight into the role of folic acid in hematopoiesis was gained through the efforts of Lucy Wills, a British hematologist, who found that extracts of yeast and liver reduce anemia and leukopenia in pregnant women. She also found that removing this antianemic factor (the socalled Wills factor) from the diet of monkeys severely reduced their red and white blood cell counts (Wills et al., 1937; Jukes, 1987). Knowledge of the Wills factor led to the discovery of folic acid. Because "folic acid concentrate" caused regression of mammary tumors in mice (Leuchtenberger et al., 1945), Sidney Farber, Louis Diamond, and their research assistants administered folic acid to 90 patients with late-stage cancers, including acute leukemia. Unexpectedly, folic acid accelerated the leukemic process to an unprecedented degree, leading to the sudden mortality of all patients. Farber concluded that folic acid conjugates should not be used to treat patients with cancer (Farber et al., 1947). Importantly, he inferred from the observed "acceleration phenomenon" that reducing folic acid levels might suppress the proliferation of malignant cells and restore normal bone marrow function. Farber proposed that a drug that chemically blocks folic acid would inhibit the abnormal marrow production associated with leukemia. In 1947, the antifolate aminopterin was synthesized (Seeger et al., 1947). In 1948, Farber 
and Diamond reported that aminopterin induced temporary remission of acute leukemia in children (Farber and Diamond, 1948). Subsequent studies noted that a deficiency of folic acid impairs hematopoiesis (Heinle and Welch, 1948; Farber, 1949). This work offered a new direction for further research on the nature and treatment of acute leukemia (Piller, 2001).

Because manufacturing aminopterin was difficult, the compound was modified to make it easier to synthesize; that modified compound was methotrexate (MTX) (Weinblatt, 2013). MTX interferes with the metabolism of folic acid. The enzyme dihydrofolate reductase (DHFR) converts dihydrofolate into tetrahydrofolate, which is a methyl-group shuttle required for the de novo synthesis of purines, thymidylate, and certain amino acids. After MTX enters a cell by using multiple uptake transporters [reviewed in Lima et al. (2014)], it is polyglutamated, binds DHFR with an affinity 1000-fold greater than that of folate, and competitively inhibits the conversion of dihydrofolate to tetrahydrofolate. Thus, MTX deprives the cell of a necessary cofactor required for the synthesis of thymidylate, a precursor to an essential building block of DNA synthesis (Fig. 1). A healthy dividing cell uses large amounts of reduced folate to maintain the ongoing synthesis of purine and thymidine; for a rapidly dividing malignant cell, the demand is even greater.

The discovery of the benefits of glucocorticoids for treating ALL built upon the findings of Dougherty and
White, who demonstrated that administration of adrenocorticotropic hormone (ACTH) reduces the size of most lymphoid tissue (Pufall, 2015). In 1949, cortisone and ACTH were shown to significantly improve rheumatoid arthritis symptoms, which led to the prediction that the combination might be an effective treatment of cancer. Either ACTH or cortisone acetate dramatically reduced the size of lymphoid tumors and leukemias but not other carcinomas (Pearson and Eliel, 1949). Despite their effective reduction of lymphoid disease, glucocorticoids given as single agents did not produce durable remissions, much less a cure. The glucocorticoid prednisone (Pred) is metabolized to prednisolone, which binds to the cytoplasmic glucocorticoid receptor and subsequently translocates to the nucleus (Fig. 1). The mechanism of cell death appears to require glucocorticoidinduced gene transcription, as its effects are blocked by inhibition of transcription by actinomycin $\mathrm{D}$ or cycloheximide, indicating a requirement for de novo transcription and translation in the execution of the apoptotic cascade (Smith and Cidlowski, 2010).

One beneficial finding from the development of chemical weapons during World War I was that exposure to mustard gas (i.e., sulfur mustard) depletes cells from the bone marrow and lymph nodes. Goodman and Gilman confirmed the antineoplastic action of nitrogen mustards against a murine lymphoma (Gilman et al., 1946). Drugs were then developed that had the same alkylating properties as the gases, and those agents

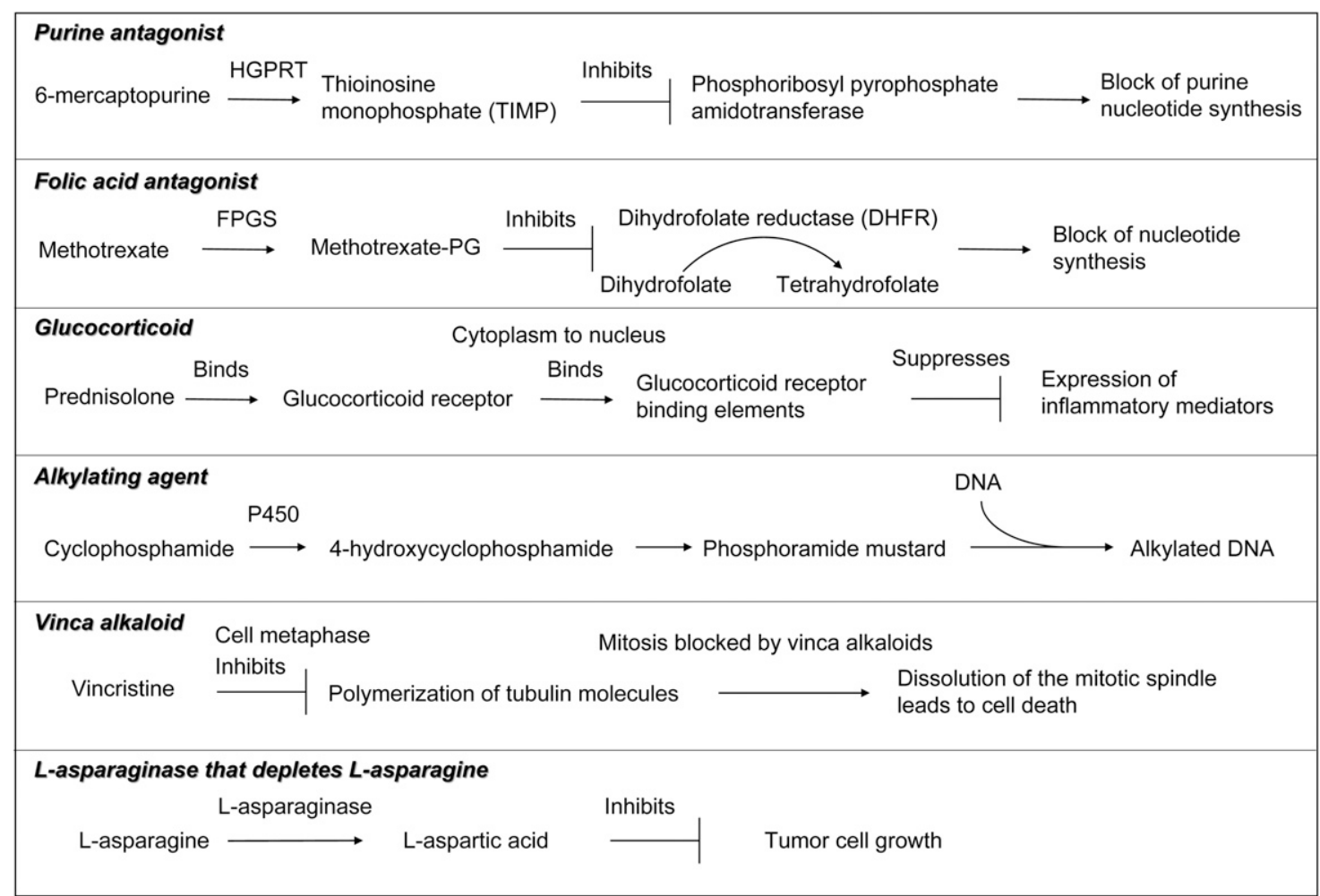

Fig. 1. Overview of the mechanisms of action of 6-mercaptopurine, methotrexate, prednisolone, cyclophosphamide, vincristine, and $L$-asparaginase. HGPRT, hypoxanthine-guanine phosphoribosyl transferase; P450, cytochrome P450. 
proved to be potent antitumor agents in clinical trials. Cyclophosphamide (CYCLO) was synthesized in 1959 to release mustard via enzymatic degradation. CYCLO causes DNA alkylation and cross-links to proteins after cytochrome P450-mediated oxidative metabolism to 4hydroxy-CYCLO (Fig. 1).

Nobel prize winners Gertrude Elion and George Hitchings synthesized another antimetabolite, 6-mercaptopurine (6-MP), in 1951 (Elion et al., 1951) and found that purine nucleotide synthesis was inhibited because of the inhibition of phosphoribosyl pyrophosphate amidotransferase, a rate-limiting step in purine synthesis (Fig. 1). Inhibition of nucleotide synthesis was effective; 6-MP showed promise in acute leukemias and other cancers (DeVita and Chu, 2008). Despite having these unique drugs to target ALL, their effectiveness in inducing remission in patients with leukemia was only temporary when given singly. For the more than 600 patients studied between 1943 and 1952, the median survival was approximately 6 weeks; $95 \%$ of the patients did not survive 12 months past diagnosis (MacMahon and Forman, 1957).

In the 1950 s, more than 120 alkaloids were discovered in the rosy periwinkle, Catharanthus roseus, including vincristine (VCR) and vinblastine. Vinca alkaloids block cell growth by interfering with microtubule polymerization, which in turn, stops mitosis (Fig. 1). The discovery that vinca alkaloids cause myelosuppression led to a study in mice with leukemia; the lifespan of the animals was dramatically prolonged by the use of a vinca alkaloid preparation (Johnson, 1968; Gidding et al., 1999).

2. The Total Therapy Approach. From the early 1950 s to the early 1960 s, Frei and Freireich conducted a series of protocols that evaluated the value of drug and dose combinations. They compared the efficacy of three therapeutic programs for acute leukemia: 1) MTX (phase I) followed by 6-MP (phase II), 2) 6-MP (phase I) followed by MTX (phase II), and 3) 6-MP given with MTX (combination therapy). In children with ALL, combination therapy achieved a superior remission rate (Frei et al., 1961). Donald Pinkel and James Holland, both at the Roswell Park Cancer Institute (Buffalo, NY), and Joe Burchenal at Memorial Sloan-Kettering Cancer Center (New York, NY) also conducted the first systematic combination chemotherapy trials for the treatment of leukemia, primarily in children (Rivera et al., 1993; Schilsky et al., 2006). Their results suggested several new ideas that changed our approach to the disease: 1) Combinations of active drugs with different modes of actions can destroy leukemia tissue in an additive manner that leaves fewer residual leukemic cells, from which a drug-resistant cell population could emerge. 2) Interruption of leukemic cell proliferation at multiple points in the cell cycle reduces the opportunity for drugresistant cells to form. 3) The combination of three or four drugs might be lethal for leukemic cells that are only partially sensitive to individual drugs. 4) Chemotherapy sustained for 2 to 3 years might more effectively eradicate leukemic cells. This approach would be particularly effective if nonproliferating leukemic cells were triggered to proliferate during remission. 5) The minority (about 20\%) of children with lymphocytic leukemia have disease that is sensitive to all antileukemic drugs when they are used sequentially. Thus, simultaneous administration of all effective drugs to these children might destroy all leukemic cells and cure the disease. 6) However, one major challenge to curing ALL was relapse. Relapse resulting in ALL infiltrating the CNS was a major reason for termination of complete remission status (Frei et al., 1961). Additional complications during relapse that posed a risk of morbidity and mortality were bleeding and infections due to a compromised immune system.

In 1962, Donald Pinkel became the first Director at St. Jude and initiated "Total therapy," a multipronged, curative approach to treating childhood ALL (Simone, 2003). Total therapy consisted of four components: remission induction, CNS-directed therapy with cranial irradiation and intrathecal MTX, intensification (or consolidation) therapy, and continuation treatment. These four components have formed the "backbone" of ALL treatments over the 58-year evolution of Total therapy and remain a mainstay today. Here, we highlight some milestones in that evolution.

a. Era 1 (1962-1967) Total I-IV: increasing survival by reducing myelosuppression. The first era of Total studies (Total I-IV) accrued patients from 1962 to 1967 and empirically employed a variety of chemotherapeutic combinations and dosages of MTX, 6-MP, VCR, Pred, and CYCLO. The multiple mechanisms of action were thought essential to achieve additive or synergistic effects and prevent the development of cells resistant to any one agent (George et al., 1968; Pinkel, 1971; Pinkel et al., 1971, 1972; Simone et al., 1972). One key to the success of this approach was the randomization included in the experimental design. Randomization systematically determines whether new innovations improve established therapies. Total I-IV demonstrated the power of combination chemotherapy, which was far superior to the sequential administration of single agents (Pinkel, 1971; Pinkel et al., 1971). The primary treatment plan consisted of three chemotherapy phases: 1) chemotherapy to induce remission; 2) short-term, high-dosage intensive chemotherapy; and 3) long-term continuation chemotherapy. The first phase was designed to induce remission of leukemia while concurrently minimizing the hazards of gastrointestinal toxicity and bone marrow depression. This was accomplished by a 4 -week regimen of Pred and VCR, which had rapid antileukemic effects without the untoward side effects (e.g., vomiting, mucosal ulceration, leukopenia, or thrombocytopenia) of other chemotherapeutics. The second phase was intensive to achieve 
complete bone marrow remission; this phase included intravenous MTX followed by intravenous 6-MP and, finally, CYCLO. The third phase was analogous to the approach used to successfully eradicate tuberculosis, which was achieved by prolonged treatment with effective drug combinations. This phase of leukemia treatment consisted of a 2- to 3-year interval of MTX, 6-MP, CYCLO, and VCR.

Giving four agents (MTX, 6-MP, CYCLO, and VCR) in full dosage (Total I-III) often caused dangerous myelosuppression; thus, Total IV (1965-1966) investigated whether such high dosages were necessary. Upon completing the intensive phase and a 2-week rest period, patients were randomized to one of two treatment schedules: half of the children received continuation chemotherapy as maximum dosages of oral 6-MP and a weekly intravenous injection of VCR, MTX, and CYCLO; the other half received the same drugs but at half the dose. In Total IV, the median durations of complete remission and hematologic remission were longer in the full-dosage group than the half-dosage group. The full-dosage chemotherapy was also superior in preventing CNS leukemia. This suggested that higher dosages of drugs might penetrate the BBB and produce drug levels sufficient to delay or block the development of CNS leukemia. Despite this promising result, relapse occurred, usually within 10 months. CNS leukemia was ultimately the major reason for the reemergence of disease.

b. Eras 2 and 3 (1967-1983) Total V-X: complete remission prolonged by intensive CNS therapy and combination chemotherapy. Overcoming CNS leukemia (despite hematologic remission) was a goal of the Total V study (1967-1968). The therapy included an increased dose of irradiation that was confined to the cranium to avoid bone marrow damage caused by spinal irradiation. To treat the spinal bone marrow and annihilate the lurking leukemia, intrathecal MTX was administered. Like its predecessors, Total V's induction therapy consisted of Pred and VCR, followed by maintenance with high-dose 6-MP, MTX, and CYCLO. These adjustments to reduce CNS relapse appeared effective; the CNS relapse rate remained significantly lower than that in Total I-IV. Thus, combination chemotherapy and CNS-directed therapy cured approximately 50\% of the patients (Aur et al., 1971).

Total VI (1968-1970) aimed to determine, in a controlled manner, the value of "prophylactic" craniospinal irradiation (CSI) to prevent CNS leukemia. Intrathecal MTX was omitted to avoid uncontrolled systemic toxicity posed by the additional chemotherapy. After entering remission, patients were randomized to either receive CSI or not. The majority (95\%) of patients who received CSI did not relapse because of CNS leukemia, whereas $65 \%$ of those who did not receive CSI did relapse, indicating that prophylactic irradiation was effective in reducing CNS leukemia (Aur et al., 1972).
An additional objective of Total VI was to determine whether an intensive course of chemotherapy early in remission would be beneficial. After patients entered remission, they were randomized to receive either 1 week of high-dosage intravenous chemotherapy composed of 6-MP, MTX, and CYCLO or no additional treatment. All subsequent chemotherapy was the same in all patients. Unfortunately, this modification did not reduce the frequency of relapse or increase the number of survivors and was eliminated from subsequent Total therapy protocols.

Although the primary goal of ALL therapy is to cure the disease, it is also crucial to achieve this by using the least-toxic methods. In Total VII (1970-1971), the efficacy and toxicity of the two forms of effective CNS prophylactic therapy were compared. Patients were randomized to receive either CSI and five doses of intrathecal MTX (as in Total V) or CSI (as in Total VI). Both forms of therapy were equally effective in preventing CNS leukemia; however, during the first 3 months of remission, the frequency of leukopenia and temporary interruption of chemotherapy was significantly greater in those who received CSI. Thus, toxic side effects and complications were associated with both therapies, and intrathecal MTX appeared ineffective at preventing CNS ALL relapse (Aur et al., 1973).

Although Pred and VCR induced remission, whether additional periodic (or pulse) reinduction treatments during remission would be of further therapeutic benefit was unknown. Patients were randomized to receive either three weekly doses of VCR and 15 days of Pred every 12 weeks or standard treatment (i.e., daily 6-MP and MTX and weekly CYCLO). The added pulses of VCR and Pred were of no significant value (Simone et al., 1972).

By the end of Total VII, the probability of long-term survival had increased to $50 \%$. However, treatment of ALL still left much to be desired: it was largely empirical; it did not prevent hematologic relapse in as many as $66 \%$ of patients; and its acute side effects ranged from merely annoying to fatal. Furthermore, the treatment had latent, long-term detrimental effects on multiple organs (e.g., gonads, brain).

Total VIII (1972-1975) was aimed at further refining the antileukemogenic effectiveness of combination therapy. The rationale was that a combination of agents might target different inherent vulnerabilities in a population of leukemic cells. However, a caveat was that the toxicity might be additive and therefore limit the dose of each agent. The question asked by this study was, "Should one give only the most effective agent(s) in relatively high dosage or try to achieve a broader spectrum of action by using a combination of agents, even though the tolerable doses of each would reduce toxicity?" The efficacy of 1 (MTX), 2 (MTX plus 6-MP), 3 (same as group 2 plus CYCLO), and 4 (same as group 3 plus arabinosyl cytosine) therapies during remission 
was evaluated. The results showed the relapse rate in patients given MTX alone was significantly greater than that of the other groups receiving combination therapy. At the conclusion of era 2, therapy modifications that reduced CNS leukemia also significantly increased event-free survival.

The beginning of era 3 in the late $1960 \mathrm{~s}$ was highlighted by studies showing that high dosages of MTX (HDMTX) promote remission among patients with relapsed ALL (Djerassi et al., 1967). In support of this, Wang et al. (1976) demonstrated that high levels of MTX in cerebrospinal fluid (CSF) suppress CNS leukemia. Total X (1979-1983) showed that by administering HDMTX, cranial irradiation could be reduced (Abromowitch et al., 1988). To ameliorate the hematopoietic and gastrointestinal toxicity of HDMTX, leucovorin (5-formyl-tetrahydrofolate) was administered; this treatment was termed "leucovorin rescue." However, leucovorin rescue was delayed many hours after MTX was given because concurrent administration might be antagonistic (MTX and leucovorin enter the cell by the same transporter, the reduced folate carrier). The success of the delay strategy is based on leukemia cells inherently forming more MTX polyglutamates (MTX-PGs), which are more potent inhibitors of DHFR and thymidylate synthase than MTX. In contrast, susceptible host tissues (e.g., the bone marrow and gastrointestinal tract) accumulate fewer MTX-PGs, which are readily displaced by the flood of the leucovorin-derived natural folate polyglutamates. Leucovorin rescue remains a key element of HDMTX therapy today.

Although HDMTX is an effective treatment of ALL, it can cause significant toxicity, especially acute kidney injury. MTX is primarily cleared by renal excretion. MTX and its metabolites can precipitate within the renal tubules, causing crystal nephropathy and, subsequently, HDMTX-associated nephrotoxicity. Because MTX is acidic, it does not form crystals when the urine has an alkaline $\mathrm{pH}$; thus, alkalinization greatly increases MTX solubility and excretion. To minimize renal toxicity during HDMTX therapy, supportive care (e.g., intense hydration and urinary alkalinization) are employed to enhance the drug's solubility.

c. Era 4 (1984-1991) Total XI-XII: dose intensification and individualized pharmacokinetic analysis to improve outcome. The eradication of drug-resistant ALL was hypothesized to require an increased intensity of induction therapy (i.e., higher doses, resulting in fewer surviving treatment-resistant leukemic cells). The premise of this study was based on the GoldieColdman hypothesis (Goldie et al., 1982), which related the development of drug-resistant cells to the tumor size and its mutation rate. Thus, chemotherapeutic elimination of a tumor required agents with nonoverlapping mechanisms of action, given at their maximum cytotoxic dose. The addition of teniposide (TEN) and cytarabine (Ara-C) to the arsenal was based on the effective cytoreduction achieved in patients with highrisk leukemia (Dahl et al., 1987). Thus, in Total XI (1984-1988), early treatment intensification improved outcome and increased the 5-year event-free survival to $70 \%$ (Rivera et al., 1991).

In Total XII (1988-1991), the benefits of therapy guided by individualized pharmacokinetics was tested. The rate of clearance of some antileukemic agents (e.g., MTX, TEN, and Ara-C) varies as much as 10-fold among children with ALL. Patients (postremission) were treated by either conventional therapy (i.e., dosing based on body surface area) or individualized therapy (i.e., dosing based on the patient's rate of drug clearance). In the individualized-therapy group, those with rapid clearance received higher doses, and those with very slow clearance received lower doses. The study showed no significant difference between the two treatments for patients with T-lineage leukemia. However, patients with B-lineage leukemia who received individualized therapy had significantly better outcomes than those who received conventional therapy. Thus, for childhood B-lineage ALL, increasing MTX dosage in patients with rapid clearance improved their outcome without increasing toxicity (Evans et al., 1998).

Long-term anticonvulsant therapy increases the systemic clearance of several antileukemic agents and is associated with lower efficacy of chemotherapy. Thus, to prevent reduced therapeutic efficacy, alternatives to enzyme-inducing anticonvulsants are recommended for patients receiving chemotherapy for ALL (Relling et al., 2000). The failure of clearance-adjusted therapy to improve the outcome in T-lineage ALL cases might have been due to inadequate MTX levels. Several studies have shown that T-lineage blasts accumulate MTX and MTX-PGs less avidly than do B-lineage blasts and suggested that higher doses might increase MTX accumulation (Barredo et al., 1994; Synold et al., 1994; Galpin et al., 1997). Indeed, the responsiveness of B-lineage ALL to MTX, compared with that of T-lineage ALL, appears to be related, in part, to folylpolyglutamate synthetase (FPGS), an enzyme that metabolizes natural folates and a broad range of folate antagonists to polyglutamate derivatives. FPGS activity in blasts from children with newly diagnosed ALL is significantly higher in B-lineage ALL (188\%) than in T-lineage ALL (37\%) (Galpin et al., 1997). Higher FPGS activity in B-lineage blasts could also explain the superior outcome in children with B-lineage ALL treated with antimetabolite therapy. Notably, in B-lineage ALL blasts, the level of MTX-PGs is significantly related to factors beyond MTX dose, and such factors might account for the increased accumulation of MTX-PGs. These factors could be lymphoblast ploidy (hyperdiploid > nonhyperdiploid) and the percentage of cells in S-phase (Synold et al., 1994) with higher FPGS and lower DHFR (Galpin et al., 1997). 
d. Eras 5 and 6 (1991-2007) Total XIII-XV: reducing CNS relapse and individualizing treatment with pharmacogenomic analysis. Total XIIIA (1991-1994) and Total XIIIB (1994-1998) studies showed reduced relapse rates by further individualizing therapy based on disease stratification and pharmacogenetics. Total XIIIA employed early intensification of intrathecal chemotherapy in patients with high-risk ALL (i.e., $22 \%$ of the total study population). This approach reduced the risk of CNS relapse to about $1 \%$ and boosted the 5-year event-free survival to $80 \%$. However, although cranial irradiation reduces CNS relapse, it causes secondary side effects, including neurocognitive deficits and endocrinopathies (Pui et al., 2003).

In Total XIIIB, treatment was modified to improve clinical outcome and reduce untoward long-term side effects. Instead of giving Pred during postremission therapy, dexamethasone (Dex) was substituted. The substitution was because Dex is superior to Pred in relation to reduced frequency of recurrence of CNS and systemic disease (Bostrom et al., 2003). Total XIIIB was at least as effective as Total XIIIA (5-year event-free survival, $80.8 \% \pm 2.6 \%$ vs. $77.6 \% \pm 3.2 \%$ ). Only $12 \%$ of the patients in Total XIIIB received CSI, compared with $22 \%$ of those in Total XIIIA. The efficacy of early intensification of intrathecal therapy (simultaneously administered MTX, hydrocortisone, and Ara-C) was confirmed, thereby paving the way to eliminating prophylactic cranial irradiation.

Total XIIIB also demonstrated that host pharmacogenetics affects the pharmacodynamics of chemotherapy and antileukemic outcome. It was the first leukemia trial to apply pharmacogenetics during therapy to guide dosing. 6-MP is an immunosuppressant and antineoplastic agent. To reduce hematopoietic toxicity and decrease risk of secondary cancers (Pui et al., 2004), 6 -MP was carefully dosed in Total XIIIB. The dosage of 6-MP given during continuation therapy was based on polymorphisms of the gene encoding thiopurine methyltransferase (TPMT). TPMT inactivates 6-MP and circumvents the formation of thioguanine nucleotides, the major active metabolites. Among patients who inherit defective TPMT alleles, severe myelosuppression was frequently observed, even among patients receiving standard doses of 6-MP, because of the high levels of thioguanine nucleotides. Patients with defective TMPT alleles received lower doses of 6-MP to reduce risk of secondary cancer in these patients (Rocha et al., 2005; Relling et al., 2006; Abaji and Krajinovic, 2017).

Total XIV (1998-1999) attempted to find optimal doses of MTX for various subtypes of ALL while also determining pharmacogenetic factors that affect MTX sensitivity. Methylenetetrahydrofolate reductase (MTHFR) catalyzes the reduction of 5,10-methylenetetrahydrofolate to 5-methyltetrahydrofolate. This study hypothesized that in patients with MTHFR deficiency, hyperhomocystinuria occurs more frequently after MTX treatment. Additionally, genetic polymorphisms in the reduced folate carrier, the transporter for cellular uptake of reduced folates (e.g., leucovorin), and MTX might cause MTX toxicity or poor response to therapy. CSF levels of homocysteine were transiently elevated in children treated with HDMTX, suggesting that HDMTX is related to seizure risk in children with leukemia. However, the plasma and CSF concentrations of homocysteine did not differ by MTHFR or reduced folate carrier genotypes, suggesting that these gene variations are unrelated to MTX sensitivity (Kishi et al., 2003).

The St. Jude Total therapy program for childhood ALL spans seven eras (Table 1). Between 1958 and 1962, before Pinkel opened the first Total therapy study, only $3 \%$ of patients with ALL survived 5 years. After continued investigation of the optimal use of antileukemic agents, improved supportive care, and precise risk assessment in several contemporary trials, the Total XV (2000-2007) study achieved a 5-year event-free survival for childhood ALL of more than $85 \%$ and 5-year overall survival of more than 90\% (Fig. 2). Notably, steps to prevent CNS leukemia were revealed during era 2 , when craniospinal irradiation and therapeutic intensification after remission induction boosted cure rates to near 70\% (Pui and Evans, 2013). Further efforts revealed that the early intensification of intrathecal therapy substantially reduced CNS relapse hazard (era 5). Finally, during era 6, with effective risk-adjusted chemotherapy, prophylactic cranial irradiation could be safely omitted from the treatment of childhood ALL. Taken together, these studies have transformed this once uniformly fatal cancer into one with a cure rate approaching $90 \%$ (Fig. 2). This is one of the pivotal success stories of modern medicine.

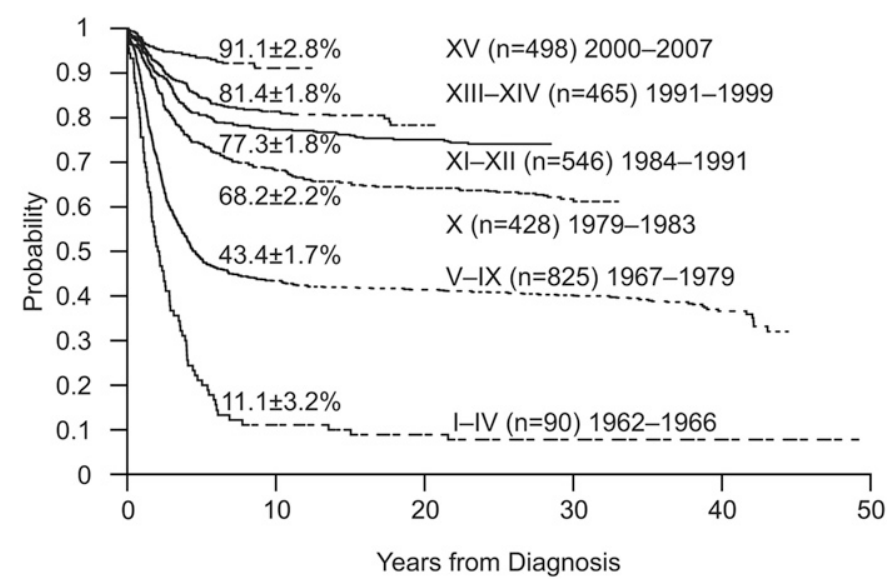

Fig. 2. Kaplan-Meier analysis of survival of 2852 children with newly diagnosed ALL who were enrolled in 1 of 15 consecutive Total therapy studies at St. Jude from 1962 to 2007. Ten-year survival estimates are shown. The results demonstrate steady improvement in outcome over the past half century. The mean ( \pm S.E.) 5-year survival probabilities are shown. Adapted from Pui and Evans (2013). 
Wijaya et al.

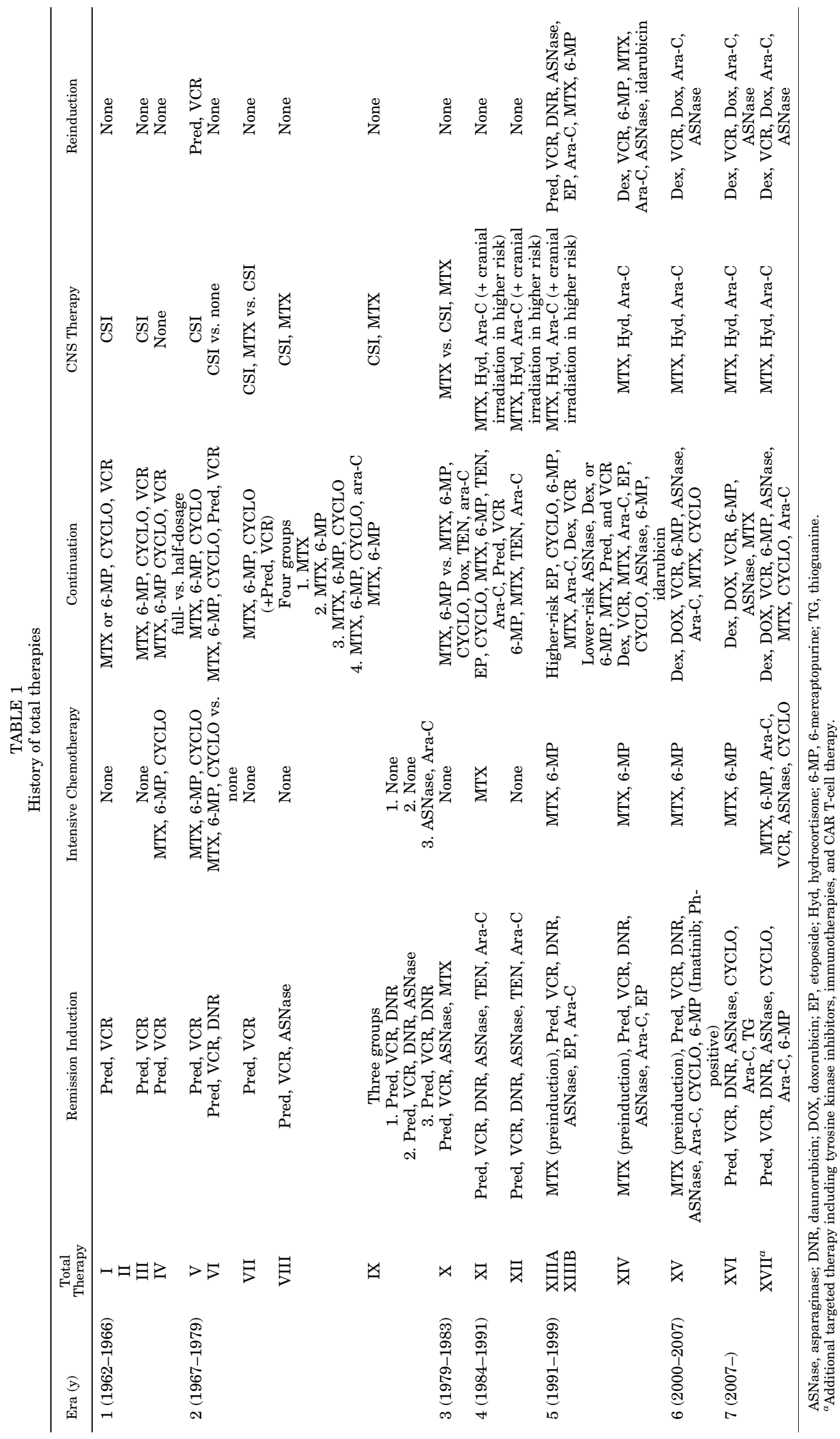


3. Improving Therapy by Understanding the Underlying ALL Biology.

a. ALL and minimal residual disease. Advances in therapy have been facilitated by both technology and an improved understanding of leukemia biology. ALL can be stratified into two main immunophenotypes identified by distinct hematopoietic lineage markers: B-ALL and T-ALL (Huntly and Gilliland, 2005). These immunophenotypes affect response to therapy, which is notable because pediatric B-ALL comprises as many as $85 \%$ of cases; T-ALL comprises the remaining $15 \%$ and is more common among male patients (Hunger and Mullighan, 2015). One crucial finding was that a submicroscopic amount of leukemia remains after remission. In 1981, immunodetection of lymphoid surface antigens by indirect immunofluorescence and antisera to human differentiation-linked antigens was used to identify residual leukemic blasts in bone marrow samples from some patients with ALL. Ultimately, multiparameter flow cytometry capable of detecting 1 in 10,000 leukemic cells revealed that this "residual" leukemia at any point after remission is predictive of relapse. This condition is referred to as minimal residual disease (MRD). Importantly, genetic abnormalities have been correlated with detectable disease at the end of remission, and the detection of MRD has become an important diagnostic assessment tool to determine the likelihood of relapse and risk stratification (Ravandi et al., 2018).

b. Genetic alterations influence ALL outcome. To determine whether the genome is altered in leukemia, it was crucial to know the accurate number of chromosomes. The ability to stratify ALL by the DNA content (i.e., ploidy) is an important feature in risk assessment. In 1978, Secker-Walker et al. (1978) classified leukemia cases into five categories based on the chromosomal characteristics of the major proportion of leukemic cells present: hyperdiploid, pseudodiploid, diploid, hypodiploid, and mixed. Patients in the hyperdiploid category had a significantly longer duration of first remission than did those in all of the other categories, and those in the pseudodiploid category had the shortest, suggesting that the proportion of hyperdiploid cells, as determined by conventional chromosomal-staining methods, can be used as an additional prognostic feature in childhood ALL.

The Philadelphia $(\mathrm{Ph})$ chromosome was the first genomic alteration in leukemia that was reported; the $\mathrm{Ph}$ chromosome was detected in myeloid leukemia (Nowell et al., 1960). Reciprocal translocation of genetic material between chromosomes 9 and 22 produces the fusion gene breakpoint cluster region-Abelson $(B C R$ $A B L) 1$ (Rowley, 1973). The fusion of the ABL kinase with BCR produces a cytosolic kinase that is an oncoprotein with constitutive kinase activity that promotes leukemogenesis by driving cell proliferation and blocking cell death (Kurzrock et al., 1988). For many years, BCR-ABL was thought to occur only in myeloid leukemias; however, Propp and Lizzi (1970) reported an adult with ALL whose marrow cells expressed a high percentage of $\mathrm{Ph}$ chromosomes.

Cytogenetic analysis was crucial to identifying gross chromosomal alterations in many childhood ALL cases. In 1984, cytogenetic analysis of leukemic cells obtained from 122 pediatric patients with ALL identified chromosomal translocations in 36 cases. Among these, two new immunophenotype-specific chromosomal translocations, $\mathrm{t}(11 ; 14)$ in T-cell ALL and $\mathrm{t}(1 ; 19)$ in pre-B-cell ALL, were associated with specific immunophenotypes of the disease. Consistent with translocations in Burkitt lymphoma, B-cell ALL, and $\mathrm{Ph}^{+} \mathrm{ALL}$, the new chromosomal rearrangements identified in pre-B-cell ALL and T-cell ALL represented specific anomalies involving defined cytogenetic loci. In cases with either $t(1 ; 19)$ or $t(11 ; 14)$, specific break points were consistently found, suggesting that genes at or near these sites have a role in leukemogenesis, leukemic cell proliferation, or both (Williams et al., 1984).

Today, we recognize multiple ALL subtypes with distinct somatic genetic alterations, including aneuploidy (changes in chromosome number); chromosomal rearrangements that deregulate gene expression or result in expression of chimeric fusion proteins, deletions, and gains of DNA; and DNA-sequence mutations (Fig. 3) (Harrison, 2009). The advent of high-resolution whole-genome and whole-transcriptome sequencing permits further classification of ALL according to its specific genetic abnormalities. Prior to these approaches, key surface proteins were identified to aid ALL stratification and classification. Importantly, a child's ALL genome harbors 10-20 nonsilent coding mutations at diagnosis, but this number increases almost 2 -fold at relapse (Ma et al., 2015). Many of these mutations perturb key cellular processes, including the transcriptional regulation of lymphoid development and differentiation; cell cycle regulation; the TP53retinoblastoma protein tumor-suppressor pathway; growth factor receptor, Ras, phosphatidylinositol 3kinase, and Janus kinase-signal transducers and activators of transcription (JAK-STAT) signaling; nucleoside metabolism; and epigenetic modification. Perturbation of the latter two processes is common at relapse (Hunger and Mullighan, 2015).

c. Applying genomics to improve therapy. An ALL with a gene-expression profile similar to that of ALL with the characteristic BCR-ABL translocation is referred to as Philadelphia chromosome-like acute lymphoblastic leukemia (Ph-like ALL); this form of the disease represents about $3 \%$ to $4 \%$ of pediatric ALL cases and about $25 \%$ of adult ALL cases. Ph-like ALL is characterized by genetic alterations that activate cytokine receptor and kinase signaling. Before the advent of tyrosine kinase inhibitors (TKIs), Ph-like ALL was associated with a very poor prognosis, despite intensive 
chemotherapy and frequent hematopoietic stem cell transplantation (Aricò et al., 2010). The development of TKIs revolutionized the therapy of Ph-like ALL. Early studies using the first-generation ABL1-class TKI, imatinib, as monotherapy in Ph-like ALL were disappointing; initial responses rapidly progressed to TKI-resistant disease. When imatinib was added to intensive chemotherapy, the survival of children with Ph-like ALL dramatically increased. In the years since the initial success of imatinib, second-generation (i.e., nilotinib, dasatinib, bosutinib) and third-generation (ponatinib) ABL1-class TKIs have been developed that are active against multiple imatinib-resistant BCR-ABL mutants (Bernt and Hunger, 2014). The standard of care for the frontline treatment of $\mathrm{Ph}^{+} \mathrm{ALL}$ consists of combinations of cytotoxic chemotherapy with TKI. Examples of clinical trials of TKI-based therapies for children, adolescents, and adults with Ph-like ALL are shown in Table 2.

One strategy to improving therapeutic efficacy is to consider how the genetic variation in host genes influences host toxicity. This area of pharmacogenomics has dramatically expanded over the past 20 years. For example, polymorphism in the TPMT, NTP diphosphatase, or ABCC4 (MRP4) gene accounts for why some patients suffer hematopoietic toxicity caused by the thiopurine regimen and others do not (Relling et al., 1999; Krishnamurthy et al., 2008; Moriyama et al., 2016). Some of these genes are considered when determining the dose of 6-MP to administer to patients in the Total studies.

d. Immunotherapy, an emerging treatment modality. Although the Total studies have proven that small molecules are efficacious in treating leukemia, immunotherapy is emerging as a promising modality. There are several immunotherapy-based approaches: bispecific T-cell engager (BiTE), antibody-drug conjugates, and most recently approved for leukemia, chimeric antigen receptor (CAR) T-cell therapy. Blinatumomab (Blincyto; Amgen), a bispecific monoclonal antibody, is a first-in-class targeted immunotherapy agent for the treatment of B-cell malignancies. Blinatumomab simultaneously binds CD19 expressed on the surface of ALL cells and CD3 expressed on T cells. The bridge formed by blinatumomab binding brings the $\mathrm{T}$ cells close enough to the ALL cells to recognize and kill them. Clinical trials have demonstrated its efficacy in relapsed B-cell ALL and B-cell non-Hodgkin lymphoma, including in patients who are refractory to chemotherapy (Kantarjian et al., 2017; Gökbuget et al., 2018).

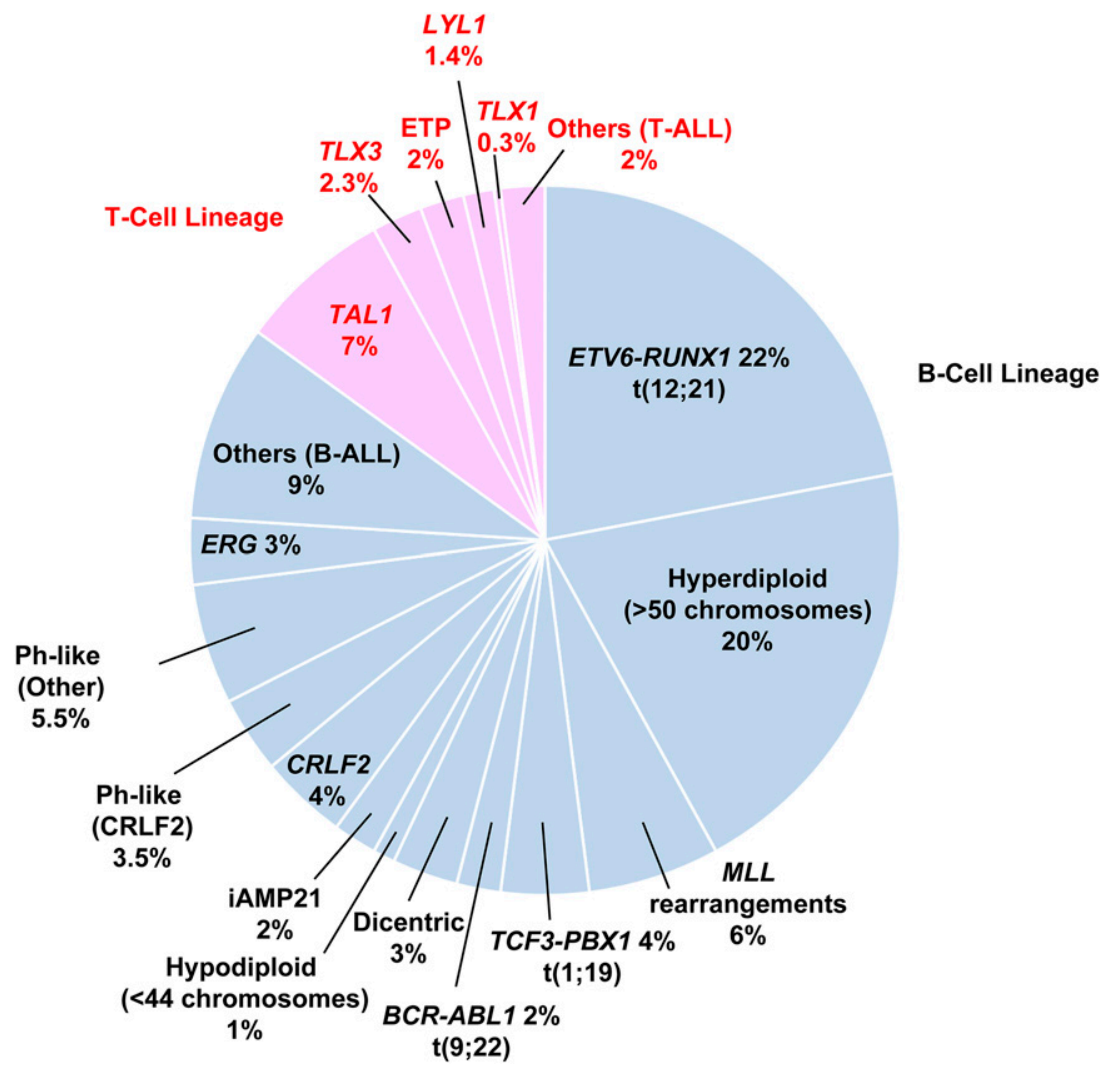

Fig. 3. Cytogenetic and molecular genetic abnormalities in childhood ALL. Abnormalities that are exclusively seen in T-cell-lineage ALL are shown in pink. Abnormalities that are commonly seen in B-cell-lineage ALL are shown in blue. ABL, Abelson; BCR, breakpoint cluster region; CRLF2, cytokine receptor-like factor 2; ERG, ETS transcription factor ERG; ETP, early T-cell precursor; ETV6, ETS variant transcription factor 6; iAMP21, intrachromosomal amplification of chromosome 21; LYL1, lymphoblastic leukemia derived sequence 1; MLL, mixed lineage leukemia; PBX1, pre-B-cell leukemia transcription factor 1; RUNX1, runt-related transcription factor 1; TAL1, T-cell acute lymphocytic leukemia protein 1; TCF3, transcription factor 3; TLX1, T cell leukemia homeobox 1; TLX3, T cell leukemia homeobox 3. 
Another strategy is drug delivery by antibody. Inotuzumab ozogamicin (InO; Besponsa), is a CD22 monoclonal antibody conjugated with calicheamicin, a natural product derivative that targets and produces double-stranded breaks in DNA (Kantarjian et al., 2012, 2013). CD22 is detected on leukemic blasts in more than $90 \%$ of patients with ALL. After the antibody portion binds to CD22 receptors on the surface of leukemic cells, the entire InO-calicheamicin conjugate enters the cell. The antibody-drug conjugate is transported through endosomes to the lysosomes, where the acidic environment hydrolyzes the inactive inotuzumab into ozogamicin. Ozogamicin is then activated by intracellular glutathione and travels to the nucleus to induce cell cycle arrest or cell death. InO was recently introduced as a targeted therapy for relapsed or refractory CD22+ B-cell precursor ALL (DeAngelo et al., 2017; Yurkiewicz et al., 2018).

CAR T-cell therapy is an emerging molecular hack of the immune system. Killer T cells are obtained from a patient and engineered to express a chimeric receptor, which in simple terms has two parts: a targeting domain that recognizes a protein on the surface of the patient's cancer cells and an activation domain. When CAR T cells bind their targeted antigen, they elicit a cytotoxic effect to trigger cancer cell death (Sadelain et al., 2013). Tisagenlecleucel (Kymriah;Novartis) is an autologous CD19-targeted CAR T-cell product approved for treatment of relapsed or refractory B-cell ALL and lymphoma (Maus and Levine, 2016). In a global study of CAR T-cell therapy, a single infusion of tisagenlecleucel provided durable remission and long-term persistence in pediatric and young adult patients with relapsed or refractory B-cell ALL, with transient high-grade toxic effects (Maude et al., 2018). The SJCAR19 trial (NCT03573700) for ALL in children and young adults is currently underway at St. Jude. These novel immunotherapies have opened an exciting new avenue of anticancer therapy, with the potential to transform the lives of many patients whose disease was hitherto considered incurable.

e. Future outlook. With increasing knowledge of biology, improved methods to detect and monitor disease, and the discovery of new therapies, it does not come as a surprise that the next generation of clinical trials and therapy combines all of these advances, and St. Jude appears at the forefront. The evolution of Total therapy over the years exemplifies St. Jude's ongoing commitment to improving patient outcomes, and it continues to be reflected in the latest protocols, including Total XVI and XVII. In Total XVI, to improve systemic and CNS disease control, the protocol included delivering chemotherapeutic drugs to the cerebrospinal fluid earlier in the treatment regimen. This resulted in reduction of CNS relapse from $5.7 \%$ in Total XV to $1.8 \%$ in Total XVI (Jeha et al., 2019). Showing St. Jude's commitment to improving patients' quality of life, this regimen spared children of prophylactic cranial radiation, even for patients with high-risk disease. In Total XVII, patients with standard or high-risk disease with more than $1 \%$ MRD at the end of remission will receive additional targeted therapy based on the genetics of the disease. Patients with refractory B-ALL will receive the immunotherapy blinatumomab or CAR T-cell therapy and proteasome inhibitor bortezomib, whereas those with alterations in the tyrosine kinase pathway will have TKIs added to their treatment regimen (NCT03117751). Importantly, results from prospective trials continue to be leveraged to improve patients' quality of life. In Total XVII, patients with high-risk centrosomal protein 72 (CEP72) TT genotype (Diouf et al., 2015) will receive reduced doses of VCR in an effort to reduce both the incidence and severity of VCRinduced peripheral neuropathy. Total XVII represents the next generation of therapy, as it not only builds on the past advances but also incorporates modern strategies, including genomic, biologic, and pharmacologic understanding of disease status to customize treatments that will improve survival and patients' quality of lives.

Looking forward, several questions arise: What is the optimal sequence to treat patients; should the usually less toxic immunotherapy be used first and the more toxic chemotherapy be reserved? Can multiple monoclonal antibodies be incorporated into one regimen? Moreover, in the current treatment era, which is evolving toward precision medicine, can we replace the adverse effects of chemotherapy with a single CAR T-cell infusion? Moreover, with the speed at which technology is complementing human intelligence, can

TABLE 2

Current clinical trials of kinase inhibitor-based therapies for children, adolescents, and adults with Ph-like ALL (Tasian et al., 2017)

\begin{tabular}{lcccc}
\hline ALL Subtype (Genetic Alterations) & Age $^{a}$ & Disease Status & Inhibitor & Trial Identifier $^{b}$ (Protocol) \\
\hline Ph-like high-risk B-cell & $1-30$ & Newly diagnosed & Dasatinib & NCT02883049 \\
Ph-like & $14-55$ & Newly diagnosed & Dasatinib & NCT03564470 \\
Ph-like (ABL-class) & $\geq 10$ & Relapse & Dasatinib & NCT02420717 (MDACC) \\
Ph-like (ABL-class) & $1-30$ & De novo & Dasatinib & NCT01406756 (COG AALL1131) \\
Ph-like (ABL-class) & $1-18$ & De novo & Dasatinib & NCT03117751 (Total XVII) \\
Ph-like (CRLF2/JAK pathway) & $\geq 10$ & Relapse & Ruxolitinib & NCT02420717 (MDACC) \\
Ph-like (CRLF2/JAK pathway) & $1-21$ & De novo & Ruxolitinib & NCT02723994 (COG AALL1521)
\end{tabular}

COG, Children's Oncology Group; CRLF2, cytokine receptor-like factor 2; MDACC, MD Anderson Cancer Center.

${ }^{a}$ Age (in years) at diagnosis.

${ }^{b}$ National clinical trial (NCT) identifiers are provided; further details about these studies are available at ClinicalTrials.gov. 
we exploit it to detect disease earlier, predict treatment response, and give patients the best chance for a good outcome? Without a doubt, we will have hints to answer these questions in the upcoming years thanks to numerous collaborative efforts across disciplines and institutions. Ultimately, all researchers are committed to serving and contributing what is best for the patients.

\section{Medulloblastoma}

\section{A. Introduction to Medulloblastoma}

Medulloblastoma (MB) is an embryonic tumor found in the posterior fossa (Rutka and Hoffman, 1996). It predominantly arises in the cerebellum and spreads to the fourth ventricle. Patients typically experience cerebellar symptoms, such as headache and incoordination, for 2 to 3 months before diagnosis (Raffel, 2004). Approximately 300-400 new cases of childhood MB occur in the United States each year, representing $9.2 \%$ of pediatric tumors. Thus, MB is one of the most common malignant brain tumors in children (Johnson et al., 2014). However, until the late 1970s, the World Health Organization's classification of childhood brain tumors was incapable of accurately discriminating between various childhood brain tumors (Rorke et al., 1985).

Here, we will describe how our understanding of MB has expanded over the years and how accurate classification of MB subtypes was essential to the development of preclinical MB disease models in which new therapeutic strategies for MB could be tested (Table 3). The identification of MB subgroups and origins of the disease has rapidly progressed recently. Although this knowledge has the potential to help identify features that are important to therapeutic response, progress in that area lags. This lag might be due to a combination of factors, such as fewer patients, more disease heterogeneity, and accessing the CNS tumor with effective agents that can cross the BBB. Nonetheless, therapy for $\mathrm{MB}$ is advancing.

\section{B. MB Classification to Understand Disease and Improve Therapy}

In 1969, Chu Chang, Edgar Housepian, and Charles Herbert introduced the Chang staging system, which used tumor size and metastatic status to categorize MBs (Chang et al., 1969). Chang stage T1 and T2 tumors are smaller than $3 \mathrm{~cm}$ in diameter and are seen infrequently, whereas T3 and T4 tumors are larger lesions that invade adjacent structures or have spread. Additionally, the team introduced the M0-M4 metastasis grading system (Chang et al., 1969), which was invaluable because MB has the propensity to metastasize; approximately $30 \%$ of children with MB present with CSF metastasis at diagnosis (Johnson et al., 2014). For CNS tumors, the Chang staging system has been important for stratifying therapy. However, in the 1980s, MB tumors were still not clearly understood by neuropathologists, as evidenced by the following comment: "In fact, they were classified together with primitive neuroectodermal tumors because they were primarily in the cerebellum with similar histological features" (Rorke et al., 1985). This unclear MB classification probably affected the disease's response to therapy. By 2007, all CNS tumors were reclassified by the World Health Organization. MB tumors were stratified into four histologic subtypes: classic, desmoplastic, MB with extensive nodularity, and large-cell/ anaplastic (Louis et al., 2007). Tumor histology has been associated with clinical outcome. For example, patients with large-cell/anaplastic tumors have significantly poorer survival than those whose $\mathrm{MB}$ has classic histology (Lamont et al., 2004).

\section{Evolution of Therapy and Impact on Mortality}

1. Surgery and Radiation Therapy. In 1925, Cushing began surgically removing MBs. Despite a staggering surgical mortality rate of more than $30 \%$, the patients who survived the procedure experienced increased survival to 17 months, compared with 6 months without tumor resection (Rutka and Hoffman, 1996). In 1953, Patterson and Farr reported a breakthrough in MB therapy: 3-year survival of $65 \%$ in patients who received CSI (Jenkin, 1996). Although the long-term cognitive side effects can be devasting, radiation therapy remains the standard of care for MB today.

As was shown for ALL, risk stratification of MB improved therapeutic outcomes. Which MB tumors must be treated aggressively? Important prognostic factors (i.e., age, amount of tumor remaining postsurgery, and the extent of metastasis, as classified by the Chang $M$ stage) are used to assign patients to either standard- or high-risk therapy (Fig. 4A). Patients with standard-risk MB have residual tumor smaller than $1.5 \mathrm{~cm}^{2}$ and no metastases; these patients receive a reduced dose $(23.4 \mathrm{~Gy})$ of radiation, a localized irradiation boost to the posterior fossa region, and adjuvant chemotherapy. Patients with high-risk MB have residual tumors larger than $1.5 \mathrm{~cm}^{2}$ and evidence of metastases; these patients receive 36 Gy radiation, a localized irradiation boost to the posterior fossa, and more-aggressive adjuvant chemotherapy (Gilbertson, 2004). Patients in the standard-risk group have an average 5-year survival of $75 \%$, compared with less than $50 \%$ for those in the high-risk group (Gilbertson, 2004). What are the therapeutic implications of such a simple binary system of tumor stratification? This scheme could jeopardize the survival of some patients by undertreating those who need more-intensive treatment. Conversely, patients might unnecessarily receive high doses of radiation if their disease is misclassified as high-risk. This binary stratification does not represent the complexity of MB; thus, by developing 


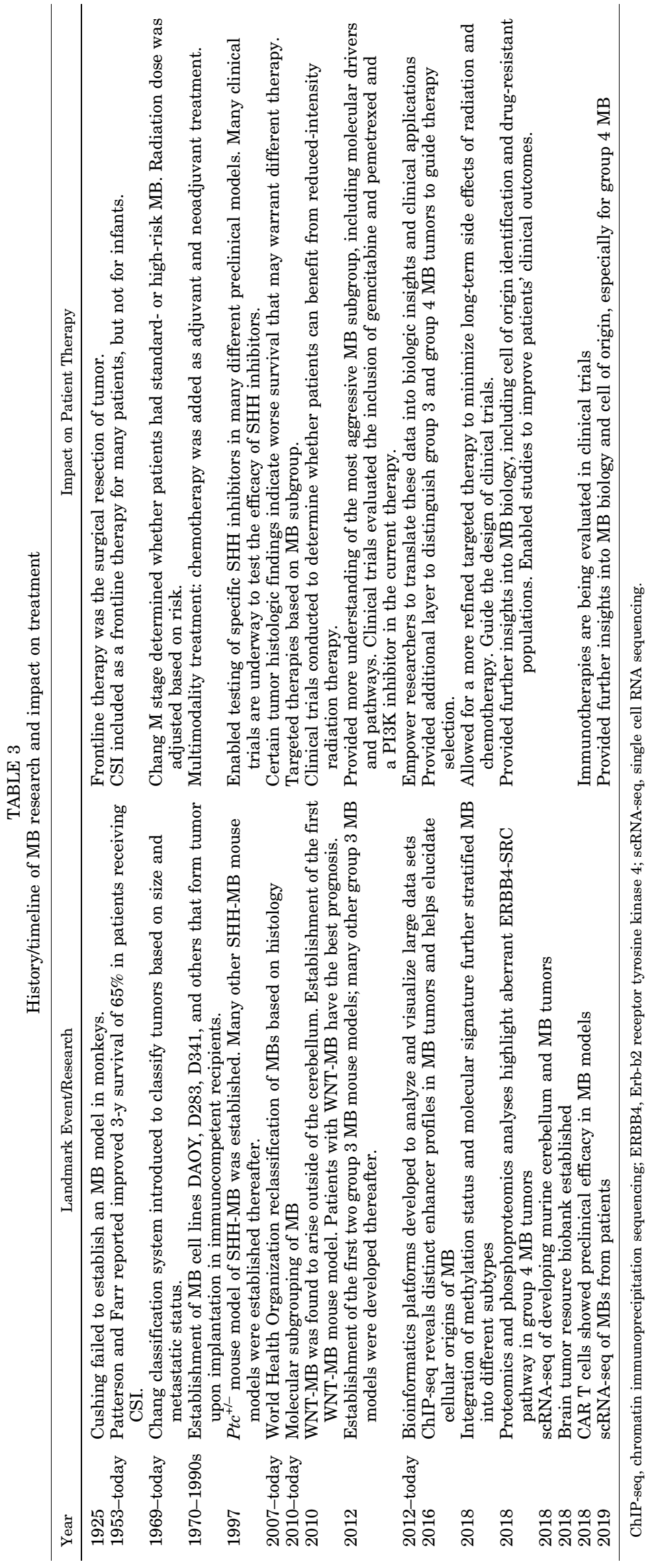


a more refined classification system, the therapeutic outcome and patients' quality of life should improve.

Epidemiologic studies suggest progress in therapy, as evidenced by the increased overall survival of patients with MB. For example, the National Cancer Institute's Surveillance, Epidemiology, and End Results program reported a 5-year survival of 45\% during 1973-1986 (Roberts et al., 1991). Increased chemotherapy implementation during 1978-1986 translated into a significant decrease in the hazard ratio and increased overall survival (Roberts et al., 1991). A 1988 report from the Children's Hospital of Philadelphia showed a 2-year disease-free survival of $96 \%$ for patients receiving radiation in combination with VCR, cisplatin, and lomustine, compared with 59\% for patients who were treated with radiation only (Packer et al., 1988). Despite the progress, the prognosis for infants was dismal (5-year survival was 20\%), with chemotherapy often prescribed to reduce the level of radiation therapy and minimize the devastating neurologic side effects of CSI (Baram et al., 1987; Loeffler et al., 1988). Some of the failure to achieve improved survival was probably due to a poor understanding of MB subtypes. In retrospect, it was fortuitous that some chemotherapy regimens were successful.
2. The Challenge of Treating CNS Tumors. In the late $1960 \mathrm{~s}$, when our understanding of cancer was naïve, one oncologist suggested that chemotherapy of brain tumors was limited by their "peculiar environment," (i.e., the BBB). The author's intended meaning was that drugs successfully used for non-CNS tumors can be effective if the BBB is circumvented. In reality, bypassing the $\mathrm{BBB}$ remains a formidable impediment to treating CNS disease. An additional challenge was that the pharmacologic properties required for a drug to bypass the BBB were mostly unknown (a "known unknown"). Today, this remains a challenge, but avoiding high lipophilicity is a main criterion for the development of such drugs (Rankovic, 2015).

Although the BBB was first described in the early 1900 s, its molecular basis was not accurately described until the late 1980s and not functionally confirmed until the 1990s (Obermeier et al., 2013). One approach to bypass the BBB is direct delivery. For example, in the late 1960s, MTX was promoted as a candidate for treating brain tumors because it had been used successfully to treat childhood ALL. Because MTX is a substrate of ABCG2, a major drug-efflux transporter at the $\mathrm{BBB}$, it does not readily penetrate the $\mathrm{BBB}$ (Jacus et al., 2016; Wijaya et al., 2017). In the early days,

A

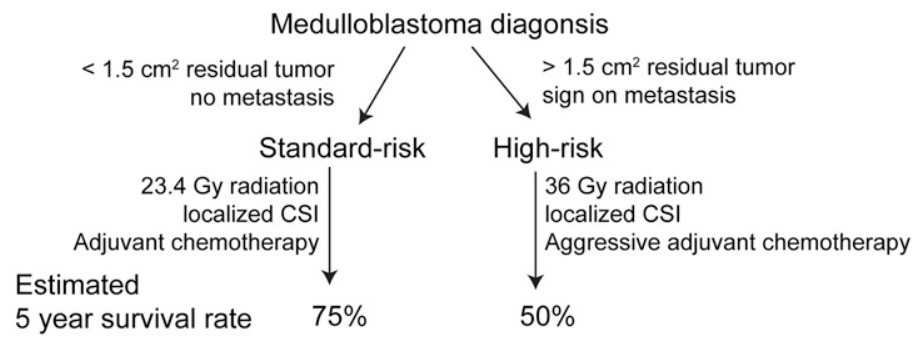

B

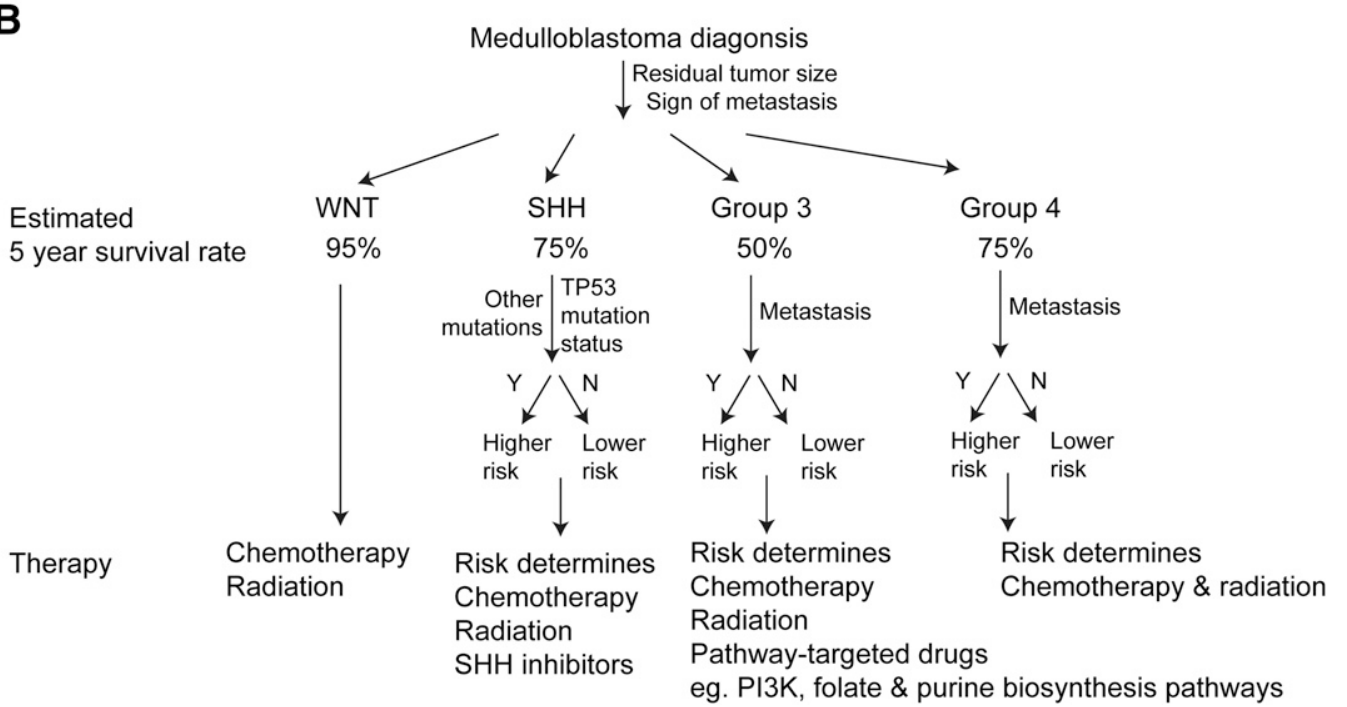

Fig. 4. Risk stratification for patients with MB. (A) MB risk stratification and treatment regimen prior to molecular subgrouping in 2010. (B) Molecular subgrouping of MB further stratified risk, resulting in more specific, individualized treatment regimens. N, No; Y, Yes. 
researchers developed a system using shunts and a brain-implanted pump that enabled intrathecal delivery of MTX (Norrell and Wilson, 1967). These same authors reported in 1969 that MTX was successfully delivered to patients with tumors of the posterior fossa (i.e., gliomas and MBs) by intrathecal delivery (Wilson and Norrell, 1969). Although this treatment was initially successful, relapse ultimately occurred. The authors recognized that the challenge at the time was their lack of basic knowledge of the growth characteristics of brain tumors. What is the tumor's generation time? How long is one cell cycle? The view of the time was that for chemotherapy to be effective, it had to be present for an entire generation period and kill a certain portion of the tumor. For brain tumors, this information was grossly lacking. As the 1970s progressed, chemotherapy supplemented surgery and radiation, but the drugs used were mostly based on successful therapies for other systemic cancers (e.g., leukemia). In fact, the approach was very empirical. As recently as 2000, the chemotherapeutic approach to MB used so-called nontargeted drugs (i.e., those that did not exploit potential tumor liabilities). These included combinations of cisplatin (a DNA cross linker)/etoposide (a topoisomerase inhibitor) and CYCLO (DNA-alkylating agent)/VCR (microtubule inhibitor) or the "Packer protocol," which included VCR, cisplatin, and lomustine (Cohen and Packer, 1996).

3. Using Molecular Subgrouping and Omics Studies to Improve Therapy. The emergence of "omics" technologies refined MB classification by using features such as a tumor's molecular gene-expression pattern. In 2010, MB experts agreed on four principle transcriptional subgroups of MB: wingless (WNT), sonic hedgehog (SHH), group 3, and group 4 (Fig. 4B) (Taylor et al., 2012). WNT and SHH are characterized by mutations in key WNT- and SHH-signaling proteins, respectively, resulting in aberrant signaling. MYC proto-oncogene, bHLH transcription factor $(M Y C)$ amplification is one of the key drivers of group $3 \mathrm{MB}$, and $M Y C N$ and $C D K 6$ (cyclin-dependent kinase) are often amplified in group 4 tumors (Northcott et al., 2012). In addition to molecular signatures, the subgrouping displays distinct demographics, histology, cytogenetics, and clinical outcome. The molecular subgroupings are valuable prognostic tools that can serve as guides toward better therapies. In 2017, such a multiomic approach integrated DNA methylation, gene expression, somatic copy-number alterations, and clinical features to further stratify MB; this study revealed two subtypes within the WNT subgroup: four within $\mathrm{SHH}$ and three each within group 3 and group 4 (Cavalli et al., 2017). The relation between this in-depth omic-based stratification and therapeutic outcome is actively investigated.

The recent molecular subgrouping of MB revealed differences in response to therapy. For example, the cure rate of patients with WNT-MB treated with conventional therapy exceeds 90\% (Northcott et al., 2012). Given the excellent prognosis with current therapy, a trial is underway to determine whether reduced-intensity radiotherapy for WNT-MB is feasible. If so, implementation of such a regimen would improve long-term quality of life (NCT02724579).

Among patients with SHH-MB, infants and children have a poorer prognosis than adults (Cavalli et al., 2017). Given the aberrant SHH signaling in these tumors, including a Smoothened (SMO) inhibitor, a regulator of the SHH pathway is beneficial against adult recurrent SHH-MB (Robinson et al., 2015). Nonetheless, molecular and clinical studies showed that the SMO inhibitor was effective only in a subset of SHH-MB that harbors mutations upstream of SMO. This strategy of "drugging SMO" to treat SHH-MB revealed three unexpected challenges: 1) The treatment causes developmental defects in the young, especially in skeletal development (Robinson et al., 2017). 2) It also results in acquired resistance, which produces tumors that harbor constitutively active SMO (due to mutation) and are aggressive and therapeutically refractory (Taipale et al., 2000; Atwood et al., 2015). 3) Patients with defects in the SHH pathway downstream of SMO [e.g., Suppressor of Fused (SUFU) mutations or Glioma associated oncogene family zinc finger 2 (GLI2) amplification] do not benefit from inclusion of an SMO inhibitor in their treatment (Robinson et al., 2018). However, other treatment options are available. An SHH-specific treatment that antagonizes GLI (Glioma associated oncogene family zinc finger) proteins, such as arsenic trioxide, is being clinically evaluated (Kim et al., 2013). The TP53 status in SHH-MB influences risk, as those with mutated TP53 are considered at high risk ( $41 \%$ overall survival vs. $81 \%$ for those with wild-type TP53) (Fig. 4B).

Approaches that identify other potential vulnerabilities in MB subtypes might be therapeutically exploited, or additional MB strata might improve our knowledge of responders. Recent examples are MB phosphoproteome and epigenetic-methylation status coupled with gene-expression profiles, which appear to be valuable. For instance, a recently published phase II clinical trial by Robinson et al. (2018) identified two distinct methylation subtypes in infants with SHH-MB: iSHH-I and iSHH-II. The iSHH-II subtype showed favorable progression-free survival in the absence of radiation and chemotherapy compared with that of the iSHH-I subtype (Robinson et al., 2018). A preclinical study in mice used phosphoproteomics to monitor SHH-MB progression and discovered that casein kinase 2 is a promising target for SHH-MB therapy, including SMO-resistant tumors (Purzner et al., 2018). Casein kinase 2 modifies the phosphorylation status of many key SHH proteins. A clinical trial (NCT03904862) is underway to test the safety and tolerability of a casein kinase 2 inhibitor in patients with SHH-MB. The 
further integration of molecular signatures into treatment might enable reduced-intensity therapy and minimize the long-term side effects of current MB treatment.

Molecular subgrouping has also uncovered pathways that drive disease and may be therapeutically tractable. For instance, the phosphatidylinositol-3-kinase (PI3K) pathway is upregulated in group $3 \mathrm{MB}$ (Pei et al., 2012, 2016). Given the promising results from preclinical models treated with PI3K inhibitors, downregulation of this pathway might improve MB outcome. Most recently, Erb-b2 recepor tyrosine kinase 3-Src protooncogene (ERBB4-SRC) signaling was found to be a hallmark of group $4 \mathrm{MB}$, as revealed by phosphoproteomic profiling (Forget et al., 2018). Although no specific drug has been proposed, this study uncovered a promising target for treating group $4 \mathrm{MB}$.

Insights into the oncogenesis and pathways of $\mathrm{MB}$ that have been gleaned over the past 10 years would not have been possible without the major technological advances that have been made. In addition to the development of faithful model systems (described in the next section), the omics tools (proteome, transcriptome, phosphoproteome, and epigenome) have been invaluable, not only in MB disease classification and stratification but also in defining the biologic properties of the disease. Genome-editing technology, especially through CRISPR, has enabled functional genomic screens in relevant model systems that identified factors affecting the SHH pathway. For example, two independent groups uncovered the critical roles of cilia in SHH signaling (Breslow et al., 2018; Pusapati et al., 2018). Because proteins are trafficked in and out of primary cilia by microtubule-based motors, these studies may validate the use of vinca alkaloids, such as VCR. The functional genomics approach can be applied to other MB subgroups to gain insight into the genes and pathways that promote their cell proliferation and drug resistance.

Recent advances in transcriptomics technology, including single-cell RNA sequencing (scRNA-seq), are most likely to help advance our knowledge of which progenitors trigger MB development (Hedlund and Deng, 2018). The ability to measure gene expression in hundreds to thousands of individual cells generates unique cell-specific signatures. In aggregate, these signatures might provide a "fingerprint" of unknown factors affecting developmental timing, which could aid in determining where development goes awry to create MB. The scRNA-seq data on developing murine cerebellum are now available, and they have revealed novel transcriptional regulators for distinct cell populations (Carter et al., 2018). Furthermore, single-cell transcriptomics will help us understand MB heterogeneity and identify specific cell populations that drive oncogenesis or drug resistance (El-Hamamy et al., 2018). Most recently, an integration of scRNA-seq performed in 25 patients with MB and mouse cerebellar scRNAseq data sets revealed that WNT-MB, SHH-MB, and group $3 \mathrm{MB}$ tumors consist of specific undifferentiated cells and differentiated neuron-like malignant cells, whereas group $4 \mathrm{MB}$ tumors are mostly differentiated neuron-like neoplastic cells (Hovestadt et al., 2019). This study suggests that glutaminergic cerebellar nuclei and unipolar brush cells within the cerebellum are the cells of origin for group $4 \mathrm{MB}$; this finding will aid in the development of group $4 \mathrm{MB}$ models and understanding the biology of this subgroup (Hovestadt et al., 2019)

\section{Development of Models to Better Understand MB Biology and Develop New Therapies}

After Cushing began removing MB tumors in 1925, he attempted to establish an animal model by implanting human MB tumor fragments into the cisterna magna of monkeys (Rutka and Hoffman, 1996). Unfortunately, his efforts were largely unsuccessful. Animal models of brain tumors are advantageous from a drugdevelopment perspective because salient features, like the amount of drug reaching the brain, the effects of route and schedule of administration, and efficacy, can be investigated. Without animal models, the strategy in the clinic was empirical-did a patient respond or not? It was challenging to determine whether brain tumors responded differently to chemotherapy than did extracerebral tumors. Since 2000, our understanding of MB has advanced, and the challenges of developing effective (and most likely tumor-tailored) MB therapy have been advanced by the development of in vitro cell model systems, genetically engineered mouse models (GEMMs), orthotopic patient-derived xenografts (O-PDXs), and other sophisticated models, including brain organoids, especially when paired with high-throughput sequencing and genome-editing technologies.

1. Immortalized Cell Lines and Those Derived from GEMMs. Many human MB cell lines, including DAOY, D283, UW228, D341, and HD-MB03, have been established since the 1980s (Friedman et al., 1985, 1988; Jacobsen et al., 1985; Keles et al., 1995; Milde et al., 2012). These lines represent different MB subgroups, thereby enabling researchers to not only study specific tumor subgroups but also use a cost-effective means to determine whether MB subgroups exhibit differences in drug response. Such differences might provide insight into the molecular signature of targetable drug pathways. One study found differential sensitivity of cells to the flavonoid quercetin as a radiosensitizer in DAOY cells, which represent SHH-MB with TP53 mutation (Jacobsen et al., 1985), compared with D458-med cells (He X et al., 1991), which represent group 3 MB (Lagerweij et al., 2016). Although the number of MB cell lines has increased, in vitro models for WNT-MB and group $4 \mathrm{MB}$ are underrepresented compared with SHH-MB and group $3 \mathrm{MB}$. 
Immortalized cell lines are amenable to genetic manipulation and drug screening. However, these studies have caveats. For instance, cell lines are maintained in environments that are nonphysiologic (e.g., $20 \% \mathrm{O}_{2}$, whereas many organs function in the range of $2 \%-8 \% \mathrm{O}_{2}$ ); the lines are prone to harboring genetically unstable genomes and can respond differently to drugs in vitro versus in vivo. For example, $M Y C$ overexpression sensitizes some MB cell lines to drugs in vitro, but this is not recapitulated in patients' response (von Bueren et al., 2011). To overcome the limitations of established cell lines, primary tumor cells from patients or cells derived for GEMMs are viable alternatives. Tumors isolated from GEMMs can grow threedimensionally as tumorspheres, are tumorigenic, and retain MB markers. For example, tumorspheres from $\mathrm{Ptch}^{+/-}$mice were used to determine that the activation of the Ras-type GTPase (RAS)/mitogen-activated protein kinase (MAPK) pathway promotes resistance to SMO inhibition (Zhao et al., 2015). Cell lines derived from group 3 MB GEMMs have shown great promise in identifying translationally important therapeutics. A clinical trial (NCT01878617) evaluating the efficacy of combining the nucleoside gemcitabine (targets DNA synthesis by inhibiting ribonucleotide reductase) and the antifolate pemetrexed with standard chemotherapy for group 3 and group $4 \mathrm{MB}$ was based on a successful highthroughput screen of a Food and Drug Administrationapproved library using mouse group 3 tumorspheres (derived from $\operatorname{Trp}_{53^{-/-}}$;Cdkn2 $\mathrm{c}^{-/-}$mice, with enforced expression of MYC) (Morfouace et al., 2014). Similarly, a screen using a group 3-derived GEMM cell line identified a PI3K/mTOR (mammalian target of rapamycin) inhibitor as a good therapeutic prospect, which has also been taken into a clinical trial (NCT03213678) (Pei et al., 2016).

The ease of genetic manipulation of GEMM-derived cell lines has enabled biologic discoveries. For example, Vo et al. (2016) found that the interaction of MYC and MIZ (MIZ-type zinc finger) is crucial for maintaining tumor stemness, which appears to affect the development of group $3 \mathrm{MB}$ in vivo. The loss of this interaction changes the disease pathology entirely, further highlighting the role of MYC and MIZ in defining subgroup identity (Vo et al., 2016). Our group found that the expression of the ATP-binding cassette transporter subfamily G member 2 (ABCG2) significantly influences group $3 \mathrm{MB}$ response to chemotherapy (Morfouace et al., 2015; Wijaya et al., 2017). Using a group 3 GEMM-derived model, we found that ABCG2 is highly expressed at the plasma membrane. Inhibition of ABCG2 function in vitro by using the ABCG2specific inhibitor fumitremorgin $\mathrm{C}$ increases the number of apoptotic tumor cells. Importantly, ABCG2 inhibition in vivo increases topotecan cytotoxicity and extends the survival of tumor-bearing mice (Morfouace et al., 2015).

\section{GEMMs.}

a. SHH-MB GEMMs. The first MB GEMM was for the SHH subgroup. The $P t c^{+/}$mouse was engineered in 1997 (Goodrich et al., 1997). By homologous recombination, part of the first and the entire second exon of Ptc was replaced with the marker gene $L a c Z$ (encoding $\beta$-galactosidase) and neomycin genes (Goodrich et al., 1997). The authors discovered that Ptc is an essential gene because homozygous deletion of Ptc was embryonically lethal (E9.0-E10.5). In contrast, the loss of one allele of Ptc produced phenotypes commonly observed in basal cell nevus syndrome (also known as Gorlin syndrome), which includes formation of extra digits in the hindlimb and an increased propensity to develop brain tumor/MB (14\%), with peak incidence between 16 and 24 weeks (Goodrich et al., 1997). Subsequent studies found that the loss of Trp53 and inactivation of one Ptc allele resulted in more than $95 \%$ of mice developing MB about 12 weeks after birth (Wetmore et al., 2000, 2001). Loss of the cyclin-dependent kinase inhibitor $\mathrm{p} 18^{\text {Ink4c }}$ in the $\mathrm{Ptc} \mathrm{c}^{+/-}$background also increased the incidence of $\mathrm{MB}$, highlighting the role of Retinoblasma protein in MB pathogenesis (Uziel et al., 2005). Similarly, the loss of p27(Kip1) cyclin-dependent kinase inhibitor in the $\mathrm{Ptc}^{+/-}$background resulted in MB with increased latency and penetrance compared with the loss of Ptc alone (Ayrault et al., 2009). These latter two GEMMs are particularly useful to model SHH-MB without the loss of the tumor suppressor TP53, which is the subtype that develops in most patients with SHHMB (Cavalli et al., 2017). Further developments in SHH-MB GEMMs include the Cre-LoxP system, which enables the inducible deletion of Ptc in specific cell types (Yang et al., 2008); Sufu ${ }^{+/-}$(Suppressor of Fused); $\operatorname{Trp}_{53^{-/-}}$mice, $60 \%$ of which develop MB within 4 months (Lee et al., 2007); and oncogenic SMO mutants, which are accurate models of drug-resistant MB tumors and those that produce leptomeningeal metastases (Hallahan et al., 2004; Hatton et al., 2008).

b. WNT-MB GEMM. For years, MB tumors were thought to arise only within the cerebellum and from granule neuron progenitors as the cell of origin (Rutka and Hoffman, 1996). However, such a monolithic perspective was changed by GEMMs. Specifically, Gibson et al. (2010) discovered that WNT tumors arise outside of the cerebellum from progenitor cells in the dorsal brainstem. Unlike SHH tumors, which are located in the cerebellar hemisphere, WNT tumors are $\mathrm{Zic}^{+}$and found in the dorsal brainstem (Gibson et al., 2010). This finding enabled the development of mouse models of the WNT-MB subgroup, which accurately resemble human WNT-MB.

Under current standard MB chemotherapeutic regimens, the WNT-MB subtype has the best overall survival, suggesting that these tumors are more responsive than other MB subtypes (Northcott et al., 2012). One well known clue was that the human WNT-MB tumors 
appeared hemorrhagic (Phoenix et al., 2016). The development of a WNT-MB GEMM provides a foundation for understanding both the hemorrhagic nature of WNTMB tumors and their overall responsiveness to therapy in vivo. Researchers found that WNT-MB tumors increase the permeability of the BBB by increasing paracrine WNT signaling (Phoenix et al., 2016). WNT-MB tumors also secrete WNT inhibitor factor 1 and Dickkopf 1 as a part of a negative-feedback loop of a constitutively active WNT-signaling pathway. The high level of WNT agonists silences WNT signaling in surrounding epithelial cells, which contribute to BBB formation. This results in tumors with compromised BBBs, which allows for increased exposure of systemic chemotherapy, such as VCR, and most likely contributes to excellent prognosis (Phoenix et al., 2016).

c. Group 3 MB GEMMs. In 2012, two group $3 \mathrm{MB}$ mouse models were independently developed (Kawauchi et al., 2012; Pei et al., 2012). One group enforced $M y c$ expression in Trp53-null cerebellar progenitor cells (Kawauchi et al., 2012), whereas the other

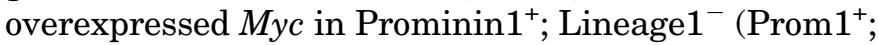
Lin $1^{-}$) cerebellar stem cells, along with a dominantnegative Trp53 (Pei et al., 2012). These models suggested that group $3 \mathrm{MB}$ can arise from different progenitors but nonetheless results in mice that developed tumors that closely resembled the most aggressive type of MB, MYC-driven MB. Tumors from these GEMMs exhibit large-cell/anaplastic histology, with a gene-expression signature closely resembling the human group 3, $M Y C$-overexpressing cohort, which is associated with the poorest prognosis (Wang et al., 2018). These GEMMs have advantages, in that the tumors isolated from these mice grow in culture indefinitely, maintain their similarity to human group 3 $\mathrm{MB}$, and have been used to identify new chemotherapeutics that are now in clinical trials, as mentioned previously. Other accurate group $3 \mathrm{MB}$ preclinical models have since emerged, including those driven by activation of growth factor independent 1 and 1B (Gfi1 and Gfi1B) in $M y c$-expressing tumors (Northcott et al., 2014), inactivation of $E z h 2$ (enhancer of zeste homolog 2) (Vo et al., 2017), and Myc upregulation by CRISPR technologies (Vo et al., 2018). These models also highlight the heterogeneity in group $3 \mathrm{MBs}$ and may be used accordingly to study different drivers of this subtype of disease.

d. Group 4 MB GEMMs. To date, there are only a few reports of group $4 \mathrm{MB}$ models, and their drivers might be heterogeneous. Targeted expression of partially stabilized Mycn (T28A) in neural stem cells isolated from postnatal day 0 cerebella produced tumors with a group 4 signature (Swartling et al., 2012). One study identified regulatory elements and core transcription factors and proposed deep cerebellar nuclei in the cerebellar nuclear transition zone or earlier precursors from the upper rhombic lip as the putative cell of origin for a subset of group $4 \mathrm{MB}$ (Lin et al., 2016). Inactivating mutations in lysine (K)-specific demethylase 6A (KDMA6), tandem duplication of synuclein alpha interacting protein (SNCAIP), and PR domain 6 (PRDM6)enhancer hijacking have also been implicated in driving group $4 \mathrm{MB}$ tumors. Until recently, molecular signatures of MB had been restricted to the genome, epigenome, and transcriptome; however, proteomic and phosphoproteomic studies suggest that posttranscriptional pathway regulation markedly differs among MB subgroups (Forget et al., 2018; Zomerman et al., 2018). Importantly, an analysis of the global correlation between transcript levels and protein levels from 41 flash-frozen primary MBs revealed a poor mRNA-protein correlation in group 4 samples, with overall higher levels of protein than mRNA (Forget et al., 2018). This study determined that aberrant receptor tyrosine kinase signaling is a hallmark of group $4 \mathrm{MB}$, suggesting that clinically approved TKIs, such as lapatinib or dasatinib, may be effective in this cohort. Phosphoproteomics also enabled the development of the second group 4 MB GEMM. Enforced expression of constitutively active SRC kinase and dominant-negative Trp53 produced tumors that do not resemble MYC-driven group $3 \mathrm{MB}$ but rather yield tumor with the molecular signature of group 4 (Forget et al., 2018).

3. $O-P D X s$. Although GEMMs have been essential to gaining insight into the MB cell(s) of origin, underlying drivers of MB subtypes, and candidate therapeutics, they have an inherent limitation-GEMMs do not capture the underlying diversity of MB subtypes seen in humans. To overcome this challenge, fresh tumors resected from patients have been implanted into the cortices of immunodeficient mice to produce O-PDXs. One advantage of this system over human cell lines in culture is that the tumors expand in vivo, in a normal physiologic environment, without ever encountering the artificial environment of a culture dish. Although expensive, O-PDX models are clinically relevant because they replicate the interindividual heterogeneity of the disease. This trait will be useful for designing individualized therapy, which has been applied for some tumors (Kawauchi et al., 2012; Brabetz et al., 2018). However, until that time, this diversity is important for revealing new therapeutic vulnerabilities of some MBs. For example, one group used different O-PDX models (i.e., $M Y C$-amplified, $M Y C$-amplified classic morphology group 3, and desmoplastic morphology SHH subgroup) to examine the efficacy of CDK4/6 inhibition and found that palbociclib suppresses tumor growth and significantly extends survival of tumorbearing mice (Cook Sangar et al., 2017). As an extension of this study, a clinical trial (NCT03709680) is evaluating palbociclib in combination with other agents for treatment of pediatric patients with recurrent/refractory solid tumors, including MB. Another group has 
used O-PDXs to study CSI dose and volume (Smith et al., 2019). Successful delivery of radiation therapy to the O-PDX model will provide a better tool for testing the timing and dosing of chemotherapeutics that closely resemble patients' treatment regimen.

4. Three-Dimensional Organoids and Other Recent Advances. In addition to immortalized cell lines and tumorspheres derived from GEMMs, an emerging model that might capture the complexity of the brain is three-dimensional organoids. Using human embryonic stem cells and the appropriate culture conditions, researchers have generated brain organoids containing functional cell types and architecture that resemble the developing fetal brain (Lancaster et al., 2013; Muguruma et al., 2015). Disease-context organoids derived from healthy donors or patients provide a novel in vitro platform for testing interindividual differences in response to chemotherapeutic agents. Furthermore, these organoids can be genetically manipulated by tools such as CRISPR-Cas9 to introduce or ablate oncogenes or tumor suppressors, thereby enabling us to learn more about tumorigenesis. Patient-derived cerebral organoids have been developed that phenocopy the patient's glioblastoma, providing a tool to investigate the disease's biology and improve therapy (Ogawa et al., 2018; Linkous et al., 2019). A MB organoid model is currently being developed (Anderle et al., 2019).

\section{E. Emerging Modalities and Future Outlook}

One of the biggest challenges in treating brain tumors (or any brain disorder) is ensuring the delivery of therapeutics across the BBB. The BBB is a neurovascular unit that limits entry of solutes and xenobiotic molecules from the blood to the CNS (Obermeier et al., 2013). BBB model systems, including rat or mouse primary immortalized endothelial cells; induced pluripotent stem cell-derived astrocytes, pericytes, and neurons; and brain organoids, provide the means to develop better brain-penetrant therapeutics ( $\mathrm{He}$ et al., 2014; Appelt-Menzel et al., 2017; Canfield et al., 2017; Bergmann et al., 2018). Therapeutic agents are screened in these systems to ensure they are not substrates of the resident ATP-dependent xenobiotics transporters ABCB1 and ABCG2 (Wijaya et al., 2017; Robey et al., 2018). A drug's physiochemical properties can be manipulated to bypass these efflux transporters and improve CNS penetration (Rankovic, 2015). In addition to small molecules, antibody-based therapies are emerging in oncology; however, the large size of antibodies limits their ability to cross the BBB. Other means of improving BBB delivery include using nanoparticles, such as dendrimers (Hayder et al., 2011), and receptor-mediated transcytosis (Jones and Shusta, 2007; Dong, 2018).

As genomic classification continues to advance small molecule-targeted therapy, emerging technologies should also be considered for treating MB. CAR T-cell therapies have recently been approved for leukemia and lymphoma and are currently being developed for solid tumors. Human epidermal growth factor 2 is overexpressed in many MB cells. Mouse O-PDXs from DAOY and D283 MB tumors treated with human epidermal growth factor receptor 2 with 4-1BB costimulatory and CD3ל CAR T cells (HER2-BBz-CAR T cells) show preclinical efficacy (Nellan et al., 2018). Another CAR T-cell target that shows great promise is B7-H3 (CD276). Intravenous administration of B7-H3 CAR T cells eradicated tumors in O-PDXs from DAOY and D425 cell lines (Majzner et al., 2019). Similarly, BiTE, which binds to antigen on cancer cells and recruits T cells, may also be considered. Although mostly used in hematologic malignancies, BiTE is being evaluated for solid tumors in ongoing studies (Cioffi et al., 2012; Kebenko et al., 2018; Fakih et al., 2019). Oncolytic viruses, which are also being evaluated in pediatric brain tumors, have several advantages: 1) they selectively replicate in cancer cells without affecting normal cells; 2) resistance to these viruses is unlikely; and 3) the stimulation of an immune response after infection makes oncolytic viruses a promising modality (Varela-Guruceaga et al., 2018). For example, rRp450 derived from herpes simplex virus-1 extends the survival of D283med and D425med MB O-PDX models (Studebaker et al., 2017). An oncolytic measles virus encoding human thyroidal sodium iodide symporter (Hutzen et al., 2012) is currently in phase I trial for MB (NCT02962167).

The therapeutic approaches described above are further enhanced by the following approaches: antibodydrug conjugates display selectivity because the antibody recognizes a unique or tumor-overexpressed antigen and eradicates the tumor by delivering a toxic molecule to it, and antisense oligonucleotides alter the level of diseasemodifying or protective mRNA. The most recent addition to the cancer therapeutic armamentarium is proteolysistargeting chimeras, which recruit the tumor's degradation machinery to degrade disease-modifying proteins (Pettersson and Crews, 2019).

All the advances described herein would not be possible without interdisciplinary collaborations. The teams acquire large-scale cancer genomic data, which are analyzed by computational biologists, validated by biologists, and then translated into information used by clinicians to design better clinical trials. Such cooperative effort requires data sharing from each functional area. Fortunately, our scientific community is open to collaboration. Websites such as cBioportal (Gao et al., 2013), R2: genomics analysis and visualization platforms (r2.amc.nl), and many others aid in data sharing and visualization of large-scale genomics data. Bioinformatics tools, such as DiSCOVER (Hanaford et al., 2016), can guide predictions for therapeutic strategy for MB based on molecular signatures of the disease. The brain tumor resource biobank (Brabetz et al., 2018) for O-PDXs enables researchers to investigate and test new 
targets and therapeutic modalities to treat MB. Studies across diverse scientific disciplines and collaborations between academic institutions and biotechnology/pharmaceutical industries will be the key to discovering the best combination of therapies for the appropriate tumor types and significantly advancing patient care and survival.

\section{Acknowledgments}

We thank Angela McArthur, St. Jude Scientific Editing, for her invaluable contributions to improving our manuscript.

\section{Authorship Contributions}

Wrote or contributed to the writing of the manuscript: Wijaya, Gose, Schuetz.

\section{References}

Abaji R and Krajinovic M (2017) Thiopurine S-methyltransferase polymorphisms in acute lymphoblastic leukemia, inflammatory bowel disease and autoimmune disorders: influence on treatment response. Pharm Genomics Pers Med 10: 143-156.

Abromowitch M, Ochs J, Pui CH, Kalwinsky D, Rivera GK, Fairclough D, Look AT, Hustu HO, Murphy SB, Evans WE, et al. (1988) High-dose methotrexate improves clinical outcome in children with acute lymphoblastic leukemia: St. Jude Total Therapy Study X. Med Pediatr Oncol 16:297-303.

Anderle M, Ballabio C, Lago C, Aiello G, and Tiberi L (2019) Medu-33. human cerebellar organoids as a new 3d model of medulloblastoma. Neuro Oncol 21:ii110.

Appelt-Menzel A, Cubukova A, Günther K, Edenhofer F, Piontek J, Krause G, Stüber T, Walles H, Neuhaus W, and Metzger M (2017) Establishment of a human bloodbrain barrier co-culture model mimicking the neurovascular unit using induced pluri- and multipotent stem cells. Stem Cell Reports 8:894-906.

Aricò M, Schrappe M, Hunger SP, Carroll WL, Conter V, Galimberti S, Manabe A Saha V, Baruchel A, Vettenranta K, et al. (2010) Clinical outcome of children with newly diagnosed Philadelphia chromosome-positive acute lymphoblastic leukemia treated between 1995 and 2005. J Clin Oncol 28:4755-4761.

Atwood SX, Sarin KY, Whitson RJ, Li JR, Kim G, Rezaee M, Ally MS, Kim J, Yao C, Chang ALS, et al. (2015) Smoothened variants explain the majority of drug resistance in basal cell carcinoma. Cancer Cell 27:342-353.

Aur RJ, Simone J, Hustu HO, Walters T, Borella L, Pratt C, and Pinkel D (1971) Central nervous system therapy and combination chemotherapy of childhood lymphocytic leukemia. Blood 37:272-281.

Aur RJA, Hustu HO, Verzosa MS, Wood A, and Simone JV (1973) Comparison of two methods of preventing central nervous system leukemia. Blood 42:349-357.

Aur RJA, Simone JV, Hustu HO, and Verzosa MS (1972) A comparative study of central nervous system irradiation and intensive chemotherapy early in remission of childhood acute lymphocytic leukemia. Cancer 29:381-391.

Ayrault O, Zindy F, Rehg J, Sherr CJ, and Roussel MF (2009) Two tumor suppressors, p27Kip1 and patched-1, collaborate to prevent medulloblastoma. $\mathrm{Mol}$ Cancer Res 7:33-40.

Baram TZ, van Eys J, Dowell RE, Cangir A, Pack B, and Bruner JM (1987) Survival and neurologic outcome of infants with medulloblastoma treated with surgery and MOPP chemotherapy. A preliminary report. Cancer 60:173-177.

Barredo JC, Synold TW, Laver J, Relling MV, Pui CH, Priest DG, and Evans WE (1994) Differences in constitutive and post-methotrexate folylpolyglutamate synthetase activity in B-lineage and T-lineage leukemia. Blood 84:564-569.

Bergmann S, Lawler SE, Qu Y, Fadzen CM, Wolfe JM, Regan MS, Pentelute BL, Agar NYR, and Cho C-F (2018) Blood-brain-barrier organoids for investigating the permeability of CNS therapeutics. Nat Protoc 13:2827-2843.

Bernt KM and Hunger SP (2014) Current concepts in pediatric Philadelphia chromosome-positive acute lymphoblastic leukemia. Front Oncol 4:54

Bessis M and Bernard J (1947) Remarquables résultats du traitement par l'exsanguino-transfusion d'un cas de leucémie aiguë. Bull Mem Soc Med Hop Paris 63:871-877.

Bostrom BC, Sensel MR, Sather HN, Gaynon PS, La MK, Johnston K, Erdmann GR Gold S, Heerema NA, Hutchinson RJ, et al.; Children's Cancer Group (2003) Dexamethasone versus prednisone and daily oral versus weekly intravenous mercaptopurine for patients with standard-risk acute lymphoblastic leukemia: a report from the Children's Cancer Group. Blood 101:3809-3817.

Brabetz S, Leary SES, Gröbner SN, Nakamoto MW, Seker-Cin H, Girard EJ, Cole B Strand AD, Bloom KL, Hovestadt V, et al. (2018) A biobank of patient-derived pediatric brain tumor models. Nat Med 24:1752-1761.

Breslow DK, Hoogendoorn S, Kopp AR, Morgens DW, Vu BK, Kennedy MC, Han K, Li A, Hess GT, Bassik MC, et al. (2018) A CRISPR-based screen for Hedgehog signaling provides insights into ciliary function and ciliopathies. Nat Genet 50: 460-471.

Canfield SG, Stebbins MJ, Morales BS, Asai SW, Vatine GD, Svendsen CN, Palecek SP, and Shusta EV (2017) An isogenic blood-brain barrier model comprising brain endothelial cells, astrocytes, and neurons derived from human induced pluripotent stem cells. $J$ Neurochem 140:874-888.

Carter RA, Bihannic L, Rosencrance C, Hadley JL, Tong Y, Phoenix TN, Natarajan S, Easton J, Northcott PA, and Gawad C (2018) A single-cell transcriptional atlas of the developing murine cerebellum. Curr Biol 28:2910-2920.e2.
Cavalli FMG, Remke M, Rampasek L, Peacock J, Shih DJH, Luu B, Garzia L, Torchia J, Nor C, Morrissy AS, et al. (2017) Intertumoral heterogeneity within medulloblastoma subgroups. Cancer Cell 31:737-754.e6.

Chang CH, Housepian EM, and Herbert C Jr. (1969) An operative staging system and a megavoltage radiotherapeutic technic for cerebellar medulloblastomas. $R a$ diology 93:1351-1359.

Cioffi M, Dorado J, Baeuerle PA, and Heeschen C (2012) EpCAM/CD3-Bispecific T-cell engaging antibody MT110 eliminates primary human pancreatic cancer stem cells. Clin Cancer Res 18:465-474.

Cohen BH and Packer RJ (1996) Chemotherapy for medulloblastomas and primitive neuroectodermal tumors. $J$ Neurooncol 29:55-68.

Cook Sangar ML, Genovesi LA, Nakamoto MW, Davis MJ, Knobluagh SE, Ji P, Millar A, Wainwright BJ, and Olson JM (2017) Inhibition of CDK4/6 by palbociclib significantly extends survival in medulloblastoma patient-derived xenograft mouse models. Clin Cancer Res 23:5802-5813.

Dahl GV, Rivera GK, Look AT, Hustu HO, Kalwinsky DK, Abromowitch M, Mirro J, Ochs J, Murphy SB, Dodge RK, et al. (1987) Teniposide plus cytarabine improves outcome in childhood acute lymphoblastic leukemia presenting with a leukocyte count greater than or equal to $100 \times 10(9) / L$, J Clin Oncol 5, pp 1015-1021.

DeAngelo DJ, Stock W, Stein AS, Shustov A, Liedtke M, Schiffer CA, Vandendries E, Liau K, Ananthakrishnan R, Boni J, et al. (2017) Inotuzumab ozogamicin in adults with relapsed or refractory CD22-positive acute lymphoblastic leukemia: a phase $1 /$ 2 study. Blood Adv 1:1167-1180.

DeVita VTJ Jr. and Chu E (2008) A history of cancer chemotherapy. Cancer Res 68 8643-8653

Diouf B, Crews KR, Lew G, Pei D, Cheng C, Bao J, Zheng JJ, Yang W, Fan Y, Wheeler HE, et al. (2015) Association of an inherited genetic variant with vincristine-related peripheral neuropathy in children with acute lymphoblastic leukemia. JAMA 313:815-823.

Djerassi I, Farber S, Abir E, and Neikirk W (1967) Continuous infusion of methotrexate in children with acute leukemia. Cancer 20:233-242.

Dong X (2018) Current strategies for brain drug delivery. Theranostics 8:1481-1493. El-Hamamy I, Vladoiu M, Donovan L, Cavalli F, Ramaswamy V, Farooq H, Lopez B, Kleinman C, Chan J, Singh S, et al. (2018) Pdtm-21. matching of single cell transcriptomics from cerebellar development identifies putative subgroup specific cells of origin for medulloblastoma. Neuro Oncol 20:vi208.

Elion GB, Hitchings GH, and Vanderwerff H (1951) Antagonists of nucleic acid derivatives. VI. Purines. J Biol Chem 192:505-518.

Evans WE, Relling MV, Rodman JH, Crom WR, Boyett JM, and Pui C-H (1998) Conventional compared with individualized chemotherapy for childhood acute lymphoblastic leukemia. N Enol J Med 338:499-505.

Fakih M, O’Neil B, Price TJ, Falchook GS, Desai J, Kuo J, Govindan R, Rasmussen E, Morrow PKH, Ngang J, et al. (2019) Phase 1 study evaluating the safety, tolerability, pharmacokinetics (PK), and efficacy of AMG 510, a novel small molecule KRAS G12C inhibitor, in advanced solid tumors. J Clin Oncol 37:3003.

Farber S (1949) Some observations on the effect of folic acid antagonists on acute leukemia and other forms of incurable cancer. Blood 4:160-167.

Farber S and Diamond LK (1948) Temporary remissions in acute leukemia in children produced by folic acid antagonist, 4-aminopteroyl-glutamic acid. $N$ Engl I Med 238:787-793.

Farber S, Cutler EC, Hawkins JW, Harrison JH, Peirce EC II, and Lenz GG (1947) The action of pteroylglutamic conjugates on man. Science 106:619-621.

Forget A, Martignetti L, Barillot E, Remke M, and Ayrault O (2018) Aberrant ERBB4-SRC signaling as a hallmark of group 4 medulloblastoma revealed by integrative phosphoproteomic profiling. Cancer Cell 34:379-395.e7.

Frei E, Freireich EJ, Gehan E, Pinkel D, Holland JF, Selawry O, Haurani F, Spurr CL, Hayes DM, James GW, et al. (1961) Studies of sequential and combination antimetabolite therapy in acute leukemia: 6-mercaptopurine and methotrexate. Blood 18:431-454.

Friedman HS, Burger PC, Bigner SH, Trojanowski JQ, Brodeur GM, He XM, Wikstrand CJ, Kurtzberg J, Berens ME, Halperin EC, et al. (1988) Phenotypic and genotypic analysis of a human medulloblastoma cell line and transplantable xenograft (D341 Med) demonstrating amplification of c-myc. Am J Pathol 130:472-484.

Friedman HS, Burger PC, Bigner SH, Trojanowski JQ, Wikstrand CJ, Halperin EC, and Bigner DD (1985) Establishment and characterization of the human medulloblastoma cell line and transplantable xenograft D283 Med. J Neuropathol Exp Neurol 44:592-605.

Galpin AJ, Schuetz JD, Masson E, Yanishevski Y, Synold TW, Barredo JC, Pui C-H Relling MV, and Evans WE (1997) Differences in folylpolyglutamate synthetase and dihydrofolate reductase expression in human B-lineage versus T-lineage leukemic lymphoblasts: mechanisms for lineage differences in methotrexate polyglutamylation and cytotoxicity. Mol Pharmacol 52:155-163.

Gao J, Aksoy BA, Dogrusoz U, Dresdner G, Gross B, Sumer SO, Sun Y, Jacobsen A Sinha R, Larsson E, et al. (2013) Integrative analysis of complex cancer genomics and clinical profiles using the cBioPortal. Sci Signal 6:pl1.

George P, Hernandez K, Hustu O, Borella L, Holton C, and Pinkel D (1968) A study of "total therapy" of acute lymphocytic leukemia in children. J Pediatr 72 (3):399-408

Gibson P, Tong Y, Robinson G, Thompson MC, Currle DS, Eden C, Kranenburg TA, Hogg T, Poppleton H, Martin J, et al. (2010) Subtypes of medulloblastoma have distinct developmental origins. Nature 468:1095-1099.

Gidding CE, Kellie SJ, Kamps WA, and de Graaf SS (1999) Vincristine revisited. Crit Rev Oncol Hematol 29:267-287.

Gilbertson RJ (2004) Medulloblastoma: signalling a change in treatment. Lancet Oncol 5:209-218.

Gilman A, Philips FS, and Hedgpeth JW (1946) The biological actions and therapeutic applications of the B-chloroethyl amines and sulfides. Science 103:409-436. Gökbuget N, Dombret H, Bonifacio M, Reichle A, Graux C, Faul C, Diedrich H, Topp MS, Brüggemann M, Horst H-A, et al. (2018) Blinatumomab for minimal residual disease in adults with B-cell precursor acute lymphoblastic leukemia. Blood 131: $1522-1531$ 
Goldie JH, Coldman AJ, and Gudauskas GA (1982) Rationale for the use of alternating non-cross-resistant chemotherapy. Cancer Treat Rep 66:439-449.

Goodrich LV, Milenković L, Higgins KM, and Scott MP (1997) Altered neural cell fates and medulloblastoma in mouse patched mutants. Science 277:1109-1113.

Hallahan AR, Pritchard JI, Hansen S, Benson M, Stoeck J, Hatton BA, Russell TL, Ellenbogen RG, Bernstein ID, Beachy PA, et al. (2004) The SmoA1 mouse model reveals that notch signaling is critical for the growth and survival of sonic hedgehog-induced medulloblastomas. Cancer Res 64:7794-7800.

Hanaford AR, Archer TC, Price A, Kahlert UD, Maciac-Zyk J, Nikkhah G, Kim JW Ehrenberger T, Clemons PA, Dan Cík V, et al. (2016) DiSCoVERing innovative therapies for rare tumors: combining genetically accurate disease models with in silico analysis to identify novel therapeutic targets. Clin Cancer Res 22:3903-3914.

Harrison CJ (2009) Cytogenetics of paediatric and adolescent acute lymphoblastic leukaemia. Br J Haematol 144:147-156.

Hatton BA, Villavicencio EH, Tsuchiya KD, Pritchard JI, Ditzler S, Pullar B, Hansen S, Knoblaugh SE, Lee D, Eberhart CG, et al. (2008) The Smo/Smo model: hedgehog-induced medulloblastoma with $90 \%$ incidence and leptomeningeal spread. Cancer Res 68:1768-1776.

Hayder M, Poupot M, Baron M, Nigon D, Turrin C-O, Caminade A-M, Majoral J-P Eisenberg RA, Fournié J-J, Cantagrel A, et al. (2011) A phosphorus-based dendrimer targets inflammation and osteoclastogenesis in experimental arthritis. Sci Transl Med 3:81ra35.

He X, Wikstrand CJ, Friedman HS, Bigner SH, Pleasure S, Trojanwski JQ and Bigner DD (1991) Differentiation characteristics of newly established medulloblastoma cell lines (D384 Med, D425 Med, and D458 Med) and their transplantable xenografts. Lab Invest 64:833-843.

He Y, Yao Y, Tsirka SE, and Cao Y (2014) Cell-culture models of the blood-brain barrier. Stroke 45:2514-2526.

Hedlund E and Deng Q (2018) Single-cell RNA sequencing: technical advancements and biological applications. Mol Aspects Med 59:36-46.

Heinle RW and Welch AD (1948) Experiments with pteroylglutamic acid and pteroylglutamic acid deficiency in human leukemia. J Clin Invest 27:539.

Hovestadt V, Smith KS, Bihannic L, Filbin MG, Shaw ML, Baumgartner A, DeWitt JC, Groves A, Mayr L, Weisman HR, et al. (2019) Resolving medulloblastoma cellular architecture by single-cell genomics. Nature 572:74-79.

Hunger SP and Mullighan CG (2015) Acute lymphoblastic leukemia in children. $N$ Engl J Med 373:1541-1552.

Huntly BJP and Gilliland DG (2005) Leukaemia stem cells and the evolution of cancer-stem-cell research. Nat Rev Cancer 5:311-321.

Hutzen B, Pierson CR, Russell SJ, Galanis E, Raffel C, and Studebaker AW (2012) Treatment of medulloblastoma using an oncolytic measles virus encoding the thyroidal sodium iodide symporter shows enhanced efficacy with radioiodine. BMC Cancer 12:508.

Jacobsen PF, Jenkyn DJ, and Papadimitriou JM (1985) Establishment of a human medulloblastoma cell line and its heterotransplantation into nude mice. $J$ Neuropathol Exp Neurol 44:472-485.

Jacus MO, Daryani VM, Harstead KE, Patel YT, Throm SL, and Stewart CF (2016) Pharmacokinetic properties of anticancer agents for the treatment of central nervous system tumors: update of the literature. Clin Pharmacokinet 55:297-311.

Jeha S, Pei D, Choi J, Cheng C, Sandlund JT, Coustan-Smith E, Campana D, Inaba H, Rubnitz JE, Ribeiro RC, et al. (2019) Improved CNS control of childhood acute lymphoblastic leukemia without cranial irradiation: St Jude total therapy study 16. J Clin Oncol 37:3377-3391.

Jenkin D (1996) The radiation treatment of medulloblastoma. $J$ Neurooncol 29 $45-54$

Johnson IS (1968) Historical background of Vinca alkaloid research and areas of future interest. Cancer Chemother Rep 52:455-461.

Johnson KJ, Cullen J, Barnholtz-Sloan JS, Ostrom QT, Langer CE, Turner MC, McKean-Cowdin R, Fisher JL, Lupo PJ, Partap S, et al. (2014) Childhood brain tumor epidemiology: a brain tumor epidemiology consortium review. Cancer Epidemiol Biomarkers Prev 23:2716-2736.

Jones AR and Shusta EV (2007) Blood-brain barrier transport of therapeutics via receptor-mediation. Pharm Res 24:1759-1771.

Jukes TH (1987) Searching for magic bullets: early approaches to chemotherapyantifolates, methotrexate--the Bruce F. Cain memorial award lecture. Cancer Res 47:5528-5536.

Kantarjian H, Stein A, Gökbuget N, Fielding AK, Schuh AC, Ribera J-M, Wei A Dombret H, Foà R, Bassan R, et al. (2017) Blinatumomab versus chemotherapy for advanced acute lymphoblastic leukemia. $N$ Engl J Med 376:836-847.

Kantarjian H, Thomas D, Jorgensen J, Jabbour E, Kebriaei P, Rytting M, York S, Ravandi F, Kwari M, Faderl S, et al. (2012) Inotuzumab ozogamicin, an anti-CD22calecheamicin conjugate, for refractory and relapsed acute lymphocytic leukaemia: a phase 2 study. Lancet Oncol 13:403-411.

Kantarjian H, Thomas D, Jorgensen J, Kebriaei P, Jabbour E, Rytting M, York S, Ravandi F, Garris R, Kwari M, et al. (2013) Results of inotuzumab ozogamicin, a CD22 monoclonal antibody, in refractory and relapsed acute lymphocytic leukemia. Cancer 119:2728-2736.

Kawauchi D, Robinson G, Uziel T, Gibson P, Rehg J, Gao C, Finkelstein D, Qu C, Pounds S, Ellison DW, et al. (2012) A mouse model of the most aggressive subgroup of human medulloblastoma. Cancer Cell 21:168-180.

Kebenko M, Goebeler M-E, Wolf M, Hasenburg A, Seggewiss-Bernhardt R, Ritter B, Rautenberg B, Atanackovic D, Kratzer A, Rottman JB, et al. (2018) A multicente phase 1 study of solitomab (MT110, AMG 110), a bispecific EpCAM/CD3 T-cell engager (BiTE®) antibody construct, in patients with refractory solid tumors. OncoImmunology 7:e1450710.

Keles GE, Berger MS, Srinivasan J, Kolstoe DD, Bobola MS, and Silber JR (1995) Establishment and characterization of four human medulloblastoma-derived cell lines. Oncol Res 7:493-503.

Kim J, Aftab BT, Tang JY, Kim D, Lee AH, Rezaee M, Kim J, Chen B, King EM, Borodovsky A, et al. (2013) Itraconazole and arsenic trioxide inhibit Hedgehog pathway activation and tumor growth associated with acquired resistance to smoothened antagonists. Cancer Cell 23:23-34.

Kishi S, Griener J, Cheng C, Das S, Cook EH, Pei D, Hudson M, Rubnitz J, Sandlund JT, Pui CH, et al. (2003) Homocysteine, pharmacogenetics, and neurotoxicity in children with leukemia. J Clin Oncol 21:3084-3091.

Krishnamurthy P, Schwab M, Takenaka K, Nachagari D, Morgan J, Leslie M, Du W, Boyd K, Cheok M, Nakauchi H, et al. (2008) Transporter-mediated protection against thiopurine-induced hematopoietic toxicity. Cancer Res 68:4983-4989.

Kurzrock R, Gutterman JU, and Talpaz M (1988) The molecular genetics of Philadelphia chromosome-positive leukemias. $N$ Engl J Med 319:990-998.

Lagerweij T, Hiddingh L, Biesmans D, Crommentuijn MHW, Cloos J, Li X-N, Kogiso M, Tannous BA, Vandertop WP, Noske DP, et al. (2016) A chemical screen for medulloblastoma identifies quercetin as a putative radiosensitizer. Oncotarget $\mathbf{7}$ 35776-35788.

Lamont JM, McManamy CS, Pearson AD, Clifford SC, and Ellison DW (2004) Combined histopathological and molecular cytogenetic stratification of medulloblastoma patients. Clin Cancer Res 10:5482-5493.

Lancaster MA, Renner M, Martin C-A, Wenzel D, Bicknell LS, Hurles ME, Homfray T, Penninger JM, Jackson AP, and Knoblich JA (2013) Cerebral organoids model human brain development and microcephaly. Nature 501:373-379.

Lee Y, Kawagoe R, Sasai K, Li Y, Russell HR, Curran T, and McKinnon PJ (2007) Loss of suppressor-of-fused function promotes tumorigenesis. Oncogene 26: $6442-6447$

Leuchtenberger R, Leuchtenberger C, Laszlo D, and Lewisohn R (1945) The influence of "folic acid" on spontaneous breast cancers in mice. Science 101:46-48.

Lima A, Bernardes M, Azevedo R, Monteiro J, Sousa H, Medeiros R, and Seabra V (2014) SLC19A1, SLC46A1 and SLCO1B1 polymorphisms as predictors of methotrexate-related toxicity in Portuguese rheumatoid arthritis patients. Toxicol Sci 142:196-209.

Lin CY, Erkek S, Tong Y, Yin L, Federation AJ, Zapatka M, Haldipur P, Kawauchi D, Risch T, Warnatz H-J, et al. (2016) Active medulloblastoma enhancers reveal subgroup-specific cellular origins. Nature 530:57-62.

Linkous A, Balamatsias D, Snuderl M, Edwards L, Miyaguchi K, Milner T, Reich B, Cohen-Gould L, Storaska A, Nakayama Y, et al. (2019) Modeling patient-derived glioblastoma with cerebral organoids. Cell Rep 26:3203-3211.e5.

Loeffler JS, Kretschmar CS, Sallan SE, LaVally BL, Winston KR, Fischer EG, and Tarbell NJ (1988) Pre-radiation chemotherapy for infants and poor prognosis children with medulloblastoma. Int J Radiat Oncol Biol Phys 15: $177-181$

Louis DN, Ohgaki H, Wiestler OD, Cavenee WK, Burger PC, Jouvet A, Scheithauer BW, and Kleihues P (2007) The 2007 WHO classification of tumours of the central nervous system. Acta Neuropathol 114:97-109.

Ma X, Edmonson M, Yergeau D, Muzny DM, Hampton OA, Rusch M, Song G, Easton J, Harvey RC, Wheeler DA, et al. (2015) Rise and fall of subclones from diagnosis to relapse in pediatric B-acute lymphoblastic leukaemia. Nat Commun 6:6604

MacMahon B and Forman D (1957) Variation in the duration of survival of patients with acute leukemia. Blood 12:683-693.

Majzner RG, Theruvath JL, Nellan A, Heitzeneder S, Cui Y, Mount CW, Rietberg SP Linde MH, Xu P, Rota C, et al. (2019) CAR T cells targeting B7-H3, a pan-cancer antigen, demonstrate potent preclinical activity against pediatric solid tumors and brain tumors. Clin Cancer Res 25:2560-2574.

Maude SL, Laetsch TW, Buechner J, Rives S, Boyer M, Bittencourt H, Bader P, Verneris MR, Stefanski HE, Myers GD, et al. (2018) Tisagenlecleucel in children and young adults with B-cell lymphoblastic leukemia. $N$ Engl $J \mathrm{Med} 378$ 439-448.

Maus MV and Levine BL (2016) Chimeric antigen receptor T-cell therapy for the community oncologist. Oncologist 21:608-617.

Milde T, Lodrini M, Savelyeva L, Korshunov A, Kool M, Brueckner LM, Antunes ASLM, Oehme I, Pekrun A, Pfister SM, et al. (2012) HD-MB03 is a novel Group 3 medulloblastoma model demonstrating sensitivity to histone deacetylase inhibitor treatment. J Neurooncol 110:335-348.

Morfouace M, Cheepala S, Jackson S, Fukuda Y, Patel YT, Fatima S, Kawauchi D, Shelat AA, Stewart CF, Sorrentino BP, et al. (2015) ABCG2 transporter expression impacts group 3 medulloblastoma response to chemotherapy. Cancer Res $\mathbf{7 5}$ 3879-3889.

Morfouace M, Shelat A, Jacus M, Freeman BBB III, Turner D, Robinson S, Zindy F, Wang Y-DD, Finkelstein D, Ayrault O, et al. (2014) Pemetrexed and gemcitabine as combination therapy for the treatment of Group3 medulloblastoma. Cancer Cell $\mathbf{2 5}$ $516-529$.

Moriyama T, Nishii R, Perez-Andreu V, Yang W, Klussmann FA, Zhao X, Lin TN, Hoshitsuki K, Nersting J, Kihira K, et al. (2016) NUDT15 polymorphisms alter thiopurine metabolism and hematopoietic toxicity. Nat Genet 48: 367-373.

Muguruma K, Nishiyama A, Kawakami H, Hashimoto K, and Sasai Y (2015) Selforganization of polarized cerebellar tissue in $3 \mathrm{D}$ culture of human pluripotent stem cells. Cell Rep 10:537-550.

Nellan A, Rota C, Majzner R, Lester-McCully CM, Griesinger AM, Mulcahy Levy JM, Foreman NK, Warren KE, and Lee DW (2018) Durable regression of Medulloblastoma after regional and intravenous delivery of anti-HER2 chimeric antigen receptor T cells. J Immunother Cancer 6:30.

Norrell H and Wilson C (1967) Brain tumor chemotherapy with methotrexate given intrathecally. A new technique. JAMA 201:93-95.

Northcott PA, Jones DTW, Kool M, Robinson GW, Gilbertson RJ, Cho Y-J, Pomeroy SL, Korshunov A, Lichter P, Taylor MD, et al. (2012) Medulloblastomics: the end of the beginning. Nat Rev Cancer 12:818-834.

Northcott PA, Lee C, Zichner T, Stütz AM, Erkek S, Kawauchi D, Shih DJH, Hovestadt V, Zapatka M, Sturm D, et al. (2014) Enhancer hijacking activates GFI1 family oncogenes in medulloblastoma. Nature 511:428-434.

Nowell P, Hungerford D, and Nowell P (1960) The minute chromosome (Phl) in chronic granulocytic leukemia. Blut 8:65-66. 
Obermeier B, Daneman R, and Ransohoff RM (2013) Development, maintenance and disruption of the blood-brain barrier. Nat Med 19:1584-1596.

Ogawa J, Pao GM, Shokhirev MN, and Verma IM (2018) Glioblastoma model using human cerebral organoids. Cell Rep 23:1220-1229.

Packer RJ, Siegel KR, Sutton LN, Evans AE, D'Angio G, Rorke LB, Bunin GR and Schut L (1988) Efficacy of adjuvant chemotherapy for patients with poor-risk medulloblastoma: a preliminary report. Ann Neurol 24:503-508.

Pearson OH Eliel LP, et al. (1949) Adrenocorticotropic hormone- and cortisoneinduced regression of lymphoid tumors in man; a preliminary report. Cancer 2 943-945.

Pei Y, Liu K-W, Wang J, Garancher A, Tao R, Esparza LA, Maier DL, Udaka YT, Murad N, Morrissy S, et al. (2016) HDAC and PI3K antagonists cooperate to inhibit growth of MYC-driven medulloblastoma. Cancer Cell 29:311-323.

Pei Y, Moore CE, Wang J, Tewari AK, Eroshkin A, Cho YJ, Witt H, Korshunov A Read TA, Sun JL, et al. (2012) An animal model of MYC-driven medulloblastoma. Cancer Cell 21:155-167.

Pettersson M and Crews CM (2019) PROteolysis TArgeting Chimeras (PROTACs) past, present and future. Drug Discov Today Technol 31:15-27.

Phoenix TN, Patmore DM, Boop S, Boulos N, Jacus MO, Patel YT, Roussel MF, Finkelstein D, Goumnerova L, Perreault S, et al. (2016) Medulloblastoma genotype dictates blood brain barrier phenotype. Cancer Cell 29:508-522.

Piller G (2001) Leukaemia - a brief historical review from ancient times to 1950. $\mathrm{Br}$ J Haematol 112:282-292.

Pinkel D (1971) Five-year follow-up of "total therapy" of childhood lymphocytic leukemia. JAMA 216:648-652

Pinkel D, Hernandez K, Borella L, Holton C, Aur R, Samoy G, and Pratt C (1971) Drug dosage and remission duration in childhood lymphocytic leukemia. Cancer 27:247-256.

Pinkel D, Simone J, Hustu HO, and Aur RJ (1972) Nine years' experience with "total therapy" of childhood acute lymphocytic leukemia. Pediatrics 50:246-251.

Propp S and Lizzi FA (1970) Philadelphia chromosome in acute lymphocytic leukemia. Blood 36:353-360.

Pufall MA (2015) Glucocorticoids and cancer. Adv Exp Med Biol 872:315-333.

Pui C-H (1995) Childhood leukemias. N Engl J Med 332:1618-1630.

Pui C-H, Cheng C, Leung W, Rai SN, Rivera GK, Sandlund JT, Ribeiro RC, Relling MV, Kun LE, Evans WE, et al. (2003) Extended follow-up of long-term survivors of childhood acute lymphoblastic leukemia [published correction appears in $N$ Engl $J$ Med (2003) 349:1299]. N Engl J Med 349:640-649.

Pui CH and Evans WE (2013) A 50-year journey to cure childhood acute lymphoblastic leukemia. Semin Hematol 50:185-196.

Pui CH, Sandlund JT, Pei D, Campana D, Rivera GK, Ribeiro RC, Rubnitz JE Razzouk BI, Howard SC, Hudson MM, et al.; Total Therapy Study XIIIB at St Jude Children's Research Hospital (2004) Improved outcome for children with acute lymphoblastic leukemia: results of Total Therapy Study XIIIB at St Jude Children's Research Hospital. Blood 104:2690-2696.

Purzner T, Purzner J, Buckstaff T, Cozza G, Gholamin S, Rusert JM, Hartl TA Sanders J, Conley N, Ge X, et al. (2018) Developmental phosphoproteomics identifies the kinase CK2 as a driver of Hedgehog signaling and a therapeutic target in medulloblastoma. Sci Signal 11.

Pusapati GV, Kong JH, Patel BB, Krishnan A, Sagner A, Kinnebrew M, Briscoe J, Aravind L, and Rohatgi R (2018) CRISPR screens uncover genes that regulate target cell sensitivity to the morphogen sonic hedgehog. Dev Cell 44:113-129.e8.

Raffel C (2004) Medulloblastoma: molecular genetics and animal models. Neoplasia 6:310-322.

Rankovic Z (2015) CNS drug design: balancing physicochemical properties for optimal brain exposure. J Med Chem 58:2584-2608.

Ravandi F, Walter RB, and Freeman SD (2018) Evaluating measurable residual disease in acute myeloid leukemia. Blood Adv 2:1356-1366.

Relling MV, Hancock ML, Rivera GK, Sandlund JT, Ribeiro RC, Krynetski EY, Pui C-H, and Evans WE (1999) Mercaptopurine therapy intolerance and heterozygosity at the thiopurine S-methyltransferase gene locus. J Natl Cancer Inst $\mathbf{9 1}$ 2001-2008.

Relling MV, Pui CH, Cheng C, and Evans WE (2006) Thiopurine methyltransferase in acute lymphoblastic leukemia. Blood 107:843-844.

Relling MV, Pui CH, Sandlund JT, Rivera GK, Hancock ML, Boyett JM, Schuetz EG, and Evans WE (2000) Adverse effect of anticonvulsants on efficacy of chemotherapy for acute lymphoblastic leukaemia. Lancet 356:285-290.

Rivera GK, Pinkel D, Simone JV, Hancock ML, and Crist WM; Jude Children's Research Hospital (1993) Treatment of acute lymphoblastic leukemia. 30 years experience at St. $N$ Engl J Med 329:1289-1295.

Rivera GK, Raimondi SC, Hancock ML, Behm FG, Pui CH, Abromowitch M, Mirro J Jr., Ochs JS, Look AT, Williams DL, et al. (1991) Improved outcome in childhood acute lymphoblastic leukaemia with reinforced early treatment and rotational combination chemotherapy. Lancet 337:61-66.

Roberts RO, Lynch CF, Jones MP, and Hart MN (1991) Medulloblastoma: a population-based study of 532 cases. J Neuropathol Exp Neurol 50:134-144.

Robey RW, Pluchino KM, Hall MD, Fojo AT, Bates SE, and Gottesman MM (2018) Revisiting the role of $\mathrm{ABC}$ transporters in multidrug-resistant cancer. Nat Rev Cancer 18:452-464.

Robinson GW, Kaste SC, Chemaitilly W, Bowers DC, Laughton S, Smith A, Gottardo NG, Partap S, Bendel A, Wright KD, et al. (2017) Irreversible growth plate fusions in children with medulloblastoma treated with a targeted hedgehog pathway inhibitor. Oncotarget 8:69295-69302.

Robinson GW, Orr BA, Wu G, Gururangan S, Lin T, Qaddoumi I, Packer RJ, Goldman S, Prados MD, Desjardins A, et al. (2015) Vismodegib exerts targeted efficacy against recurrent sonic hedgehog-subgroup medulloblastoma: results from phase II pediatric brain tumor consortium studies PBTC-025B and PBTC-032. J Clin Oncol 33:2646-2654.

Robinson GW, Rudneva VA, Buchhalter I, Billups CA, Waszak SM, Smith KS, Bowers DC, Bendel A, Fisher PG, Partap S, et al. (2018) Risk-adapted therapy for young children with medulloblastoma (SJYC07): therapeutic and molecular outcomes from a multicentre, phase 2 trial. Lancet Oncol 19:768-784.

Rocha JCC, Cheng C, Liu W, Kishi S, Das S, Cook EH, Sandlund JT, Rubnitz J, Ribeiro R, Campana D, et al. (2005) Pharmacogenetics of outcome in children with acute lymphoblastic leukemia. Blood 105:4752-4758.

Rorke LB, Gilles FH, Davis RL, and Becker LE (1985) Revision of the World Health Organization classification of brain tumors for childhood brain tumors. Cancer $\mathbf{5 6}$ (7 Suppl):1869-1886

Rowley JD (1973) Letter: a new consistent chromosomal abnormality in chronic myelogenous leukaemia identified by quinacrine fluorescence and Giemsa staining. Nature 243:290-293.

Rutka JT and Hoffman HJ (1996) Medulloblastoma: a historical perspective and overview. $J$ Neurooncol 29:1-7.

Sadelain M, Brentjens R, and Rivière I (2013) The basic principles of chimeric antigen receptor design. Cancer Discov 3:388-398.

Schilsky RL, McIntyre OR, Holland JF, and Frei E III (2006) A concise history of the cancer and leukemia group B. Clin Cancer Res 12:3553s-3555s.

Secker-Walker LM, Lawler SD, and Hardisty RM (1978) Prognostic implications of chromosomal findings in acute lymphoblastic leukaemia at diagnosis. $B M J 2$ : $1529-1530$

Seeger DR, Smith JMJ Jr., and Hultquist ME (1947) Antagonist for pteroylglutamic acid. J Am Chem Soc 69:2567.

Simone JV (2003) A history of St jude Children's research hospital. Br J Haematol 120:549-555.

Simone J, Aur RJ, Hustu HO, and Pinkel D (1972) "Total therapy" studies of acute lymphocytic leukemia in children. Current results and prospects for cure. Cancer 30:1488-1494.

Smith LK and Cidlowski JA (2010) Glucocorticoid-induced apoptosis of healthy and malignant lymphocytes. Prog Brain Res 182:1-30.

Smith SMC, Bianski BM, Orr BA, Harknett G, Onar-Thomas A, Gilbertson RJ, Merchant TE, Roussel MF, and Tinkle CL (2019) Preclinical modeling of imageguided craniospinal irradiation for very-high-risk medulloblastoma. Int $J$ Radiat Oncol Biol Phys 103:728-737.

Studebaker AW, Hutzen BJ, Pierson CR, Haworth KB, Cripe TP, Jackson EM, and Leonard JR (2017) Oncolytic herpes virus rRp450 shows efficacy in orthotopic xenograft group 3/4 medulloblastomas and atypical teratoid/rhabdoid tumors. Mol Ther Oncolytics 6:22-30.

Swartling FJ, Savov V, Persson AI, Chen J, Hackett CS, Northcott PA, Grimmer MR, Lau J, Chesler L, Perry A, et al. (2012) Distinct neural stem cell populations give rise to disparate brain tumors in response to N-MYC. Cancer Cell 21: 601-613

Synold TW, Relling MV, Boyett JM, Rivera GK, Sandlund JT, Mahmoud H, Crist WM, Pui CH, and Evans WE (1994) Blast cell methotrexate-polyglutamate accumulation in vivo differs by lineage, ploidy, and methotrexate dose in acute lymphoblastic leukemia. $J$ Clin Invest 94:1996-2001.

Taipale J, Chen JK, Cooper MK, Wang B, Mann RK, Milenkovic L, Scott MP, and Beachy PA (2000) Effects of oncogenic mutations in Smoothened and Patched can be reversed by cyclopamine. Nature 406:1005-1009.

Tasian SK, Loh ML, and Hunger SP (2017) Philadelphia chromosome-like acute lymphoblastic leukemia. Blood 130:2064-2072.

Taylor MD, Northcott PA, Korshunov A, Remke M, Cho Y-J, Clifford SC, Eberhart CG, Parsons DW, Rutkowski S, Gajjar A, et al. (2012) Molecular subgroups of medulloblastoma: the current consensus. Acta Neuropathol 123:465-472.

Terwilliger T and Abdul-Hay M (2017) Acute lymphoblastic leukemia: a comprehensive review and 2017 update. Blood Cancer $J$ 7:e577.

Uziel T, Zindy F, Xie S, Lee Y, Forget A, Magdaleno S, Rehg JE, Calabrese C, Solecki D, Eberhart CG, et al. (2005) The tumor suppressors Ink4c and p53 collaborate independently with Patched to suppress medulloblastoma formation. Genes Dev 19:2656-2667.

Varela-Guruceaga M, Tejada-Solís S, García-Moure M, Fueyo J, Gomez-Manzano C, Patiño-García A, and Alonso MM (2018) Oncolytic viruses as therapeutic tools for pediatric brain tumors. Cancers (Basel) $\mathbf{1 0}$

Vo BT, Kwon JA, Li C, Finkelstein D, Xu B, Orr BA, Sherr CJ, and Roussel MF (2018) Mouse medulloblastoma driven by CRISPR activation of cellular Myc. Sci Rep 8: 8733.

Vo BT, Li C, Morgan MA, Theurillat I, Finkelstein D, Wright S, Hyle J, Smith SMC, Fan Y, Wang Y-D, et al. (2017) Inactivation of Ezh2 upregulates Gfi1 and drives aggressive myc-driven group 3 medulloblastoma. Cell Rep 18: 2907-2917.

Vo BT, Wolf E, Kawauchi D, Gebhardt A, Rehg JE, Finkelstein D, Walz S, Murphy BL, Youn YH, Han Y-G, et al. (2016) The interaction of myc with Miz1 defines medulloblastoma subgroup identity. Cancer Cell 29:5-16

on Bueren AO, Oehler C, Shalaby T, von Hoff K, Pruschy M, Seifert B, Gerber NU, Warmuth-Metz M, Stearns D, Eberhart CG, et al. (2011) c-MYC expression sensitizes medulloblastoma cells to radio- and chemotherapy and has no impact on response in medulloblastoma patients. BMC Cancer 11:74.

Wang J, Garancher A, Ramaswamy V, and Wechsler-Reya RJ (2018) Medulloblastoma: from molecular subgroups to molecular targeted therapies. Annu Rev Neurosci 41:207-232.

Wang JJ, Freeman AI, and Sinks LF (1976) Treatment of acute lymphocytic leukemia by high-dose intravenous methotrexate. Cancer Res 36:1441-1444.

Weinblatt ME (2013) Methotrexate in rheumatoid arthritis: a quarter century of development. Trans Am Clin Climatol Assoc 124:16-25.

Wetmore C, Eberhart DE, and Curran T (2000) The normal patched allele is expressed in medulloblastomas from mice with heterozygous germ-line mutation of patched. Cancer Res 60:2239-2246.

Wetmore C, Eberhart DE, and Curran T (2001) Loss of p53 but not ARF accelerates medulloblastoma in mice heterozygous for patched. Cancer Res 61:513-516.

Wijaya J, Fukuda Y, and Schuetz JD (2017) Obstacles to brain tumor therapy: key ABC transporters. Int J Mol Sci 18 
Williams DL, Look AT, Melvin SL, Roberson PK, Dahl G, Flake T, and Stass S (1984) New chromosomal translocations correlate with specific immunophenotypes of childhood acute lymphoblastic leukemia. Cell 36:101-109.

Wills L, Clutterbuck PW, and Evans BD (1937) A new factor in the production and cure of macrocytic anaemias and its relation to other haemopoietic principles curative in pernicious anaemia. Biochem $J$ 31:2136-2147.

Wilson CB and Norrell HA Jr. (1969) Brain tumor chemotherapy with intrathecal methotrexate. Cancer 23:1038-1045.

Yang Z-J, Ellis T, Markant SL, Read T-A, Kessler JD, Bourboulas M, Schüller U, Machold R, Fishell G, Rowitch DH, et al. (2008) Medulloblastoma can be initiated by deletion of Patched in lineage-restricted progenitors or stem cells. Cancer Cell 14:135-145.
Yurkiewicz IR, Muffly L, and Liedtke M (2018) Inotuzumab ozogamicin: a CD22 mAb-drug conjugate for adult relapsed or refractory B-cell precursor acute lymphoblastic leukemia. Drug Des Devel Ther 12:2293-2300.

Zhao X, Ponomaryov T, Ornell KJ, Zhou P, Dabral SK, Pak E, Li W, Atwood SX, Whitson RJ, Chang ALS, et al. (2015) RAS/MAPK activation drives resistance to smo inhibition, metastasis, and tumor evolution in shh pathway-dependent tumors. Cancer Res 75:3623-3635.

Zomerman WW, Plasschaert SLA, Conroy S, Scherpen FJ, Meeuwsen-de Boer TGJ, Lourens HJ, Guerrero Llobet S, Smit MJ, Slagter-Menkema L, Seitz A, et al. (2018) Identification of two protein-signaling States delineating transcriptionally heterogeneous human medulloblastoma. Cell Rep 22:3206-3216. 